Review

\title{
Superabsorbent hydrogels based on polysaccharides for application in agriculture as soil conditioner and nutrient carrier: A review
}

\author{
Marcos R. Guilherme ${ }^{a}$, Fauze A. Aouada ${ }^{b}$, André R. Fajardo ${ }^{c}$, Alessandro F. Martins ${ }^{a, d}$, \\ Alexandre T. Paulino ${ }^{\mathrm{e}}$, Magali F.T. Davi ${ }^{\mathrm{f}}$, Adley F. Rubira ${ }^{\mathrm{a}}$, Edvani C. Muniz ${ }^{\mathrm{a}, \mathrm{f}, *}$ \\ a Departamento de Química, Universidade Estadual de Maringá (UEM), Av. Colombo, 5790, 87020-900 Maringá, PR, Brazil \\ ${ }^{\mathrm{b}}$ Departamento de Física e Química, Faculdade de Engenharia de Ilha Solteira, UNESP, 15385-000 Ilha Solteira, SP, Brazil \\ ${ }^{\mathrm{C}}$ Centro de Ciências Químicas, Farmacêuticas e de Alimentos (CCQFA), Universidade Federal de Pelotas, 96010-900 Pelotas, RS, Brazil \\ ${ }^{\mathrm{d}}$ Universidade Tecnológica Federal do Paraná (UTFPR-DV) - Estrada para Boa Esperança, 85660-000 Dois Vizinhos, PR, Brazil \\ e Universidade do Estado de Santa Catarina, Centro de Ensino Superior do Oeste, Dep. de Engenharia de Alimentos, Pinhalzinho, Chapecó 89870-000, SC, Brazil \\ ${ }^{\mathrm{f}}$ Universidade Paranaense, UNIPAR - Programa de Pós-graduação em Biotecnologia Aplicada à Agricultura, 87502-210 Umuarama, PR, Brazil
}

\section{A R T I C L E I N F O}

\section{Article history:}

Received 29 December 2014

Received in revised form 9 March 2015

Accepted 14 April 2015

Available online 22 April 2015

\section{Keywords:}

Superabsorbent hydrogels

Polysaccharide-based hydrogels

Superabsorbent hydrogels applied to

agriculture

Soil conditioners

Plant-nutrient carriers

\begin{abstract}
A B S T R A C T
Superabsorbent hydrogels $(\mathrm{SH})$ continue being a very important issue in both academic and industrial fields due to their applications in several technologies. This is proved by the impressive number of publications, through papers and patents as well, dealing with $\mathrm{SH}$. This review is targeted to update and discuss some important aspects of synthesis, characterization and application of SH in agriculture, mainly those based on polysaccharides, as soil conditioners and as polymer carriers for nutrient release. Basic properties of $\mathrm{SH}$ and some methods for chemically modifying polysaccharides are given and some directions for hydrogels preparation are highlighted as well. Mechanisms associated with water transport into the 3D matrix, taking into account the transference of mass from hydrogelsoil system to plant, are discussed in the light of some mathematical models. Release of nutrients either from granules coated by hydrophilic polymer or from $\mathrm{SH}$, targeting applications in agriculture, is also discussed on the basis of often used mathematical models (the swelling-based kinetic models) and on a diffusion-based kinetic model with a partition activity coefficient. Examples of recent applications in agriculture as soil conditioners and carriers for nutrient release (fertilizers, etc.) are given. At the final, future trends and perspectives are considered. More than two hundreds references are cited in the whole text.
\end{abstract}

(c) 2015 Elsevier Ltd. All rights reserved.

\section{Contents}

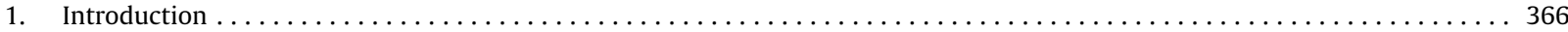

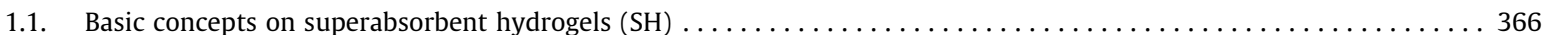

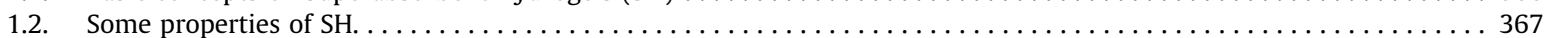

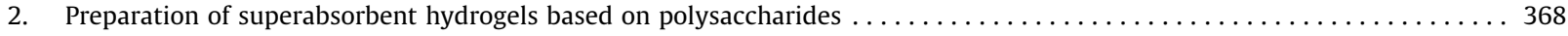

\footnotetext{
* Corresponding author at: Departamento de Química, Universidade Estadual de Maringá (UEM), Av. Colombo, 5790, 87020-900 Maringá, PR, Brazil. E-mail address: ecmuniz@uem.br (E.C. Muniz).
} 
2.1. Chemical modification of polysaccharides towards hydrogel formation $\ldots \ldots \ldots \ldots \ldots \ldots \ldots \ldots \ldots \ldots \ldots \ldots \ldots \ldots \ldots$

2.2. Chemical hydrogels based on different vinyl-modified polysaccharides through addition of methacrylate groups..... 368

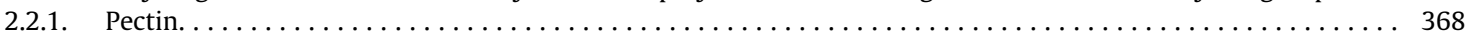

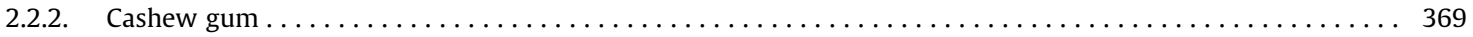

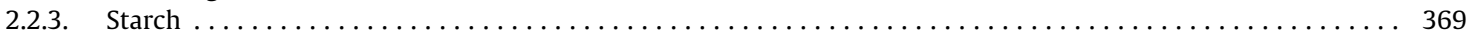

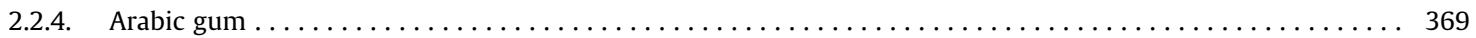

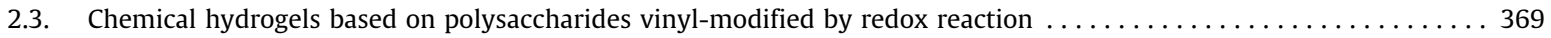

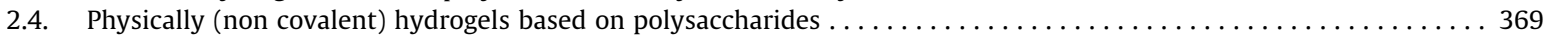

2.4.1. Polysaccharide-based hydrogels prepared by emulsion technology $\ldots \ldots \ldots \ldots \ldots \ldots \ldots \ldots \ldots \ldots \ldots \ldots$

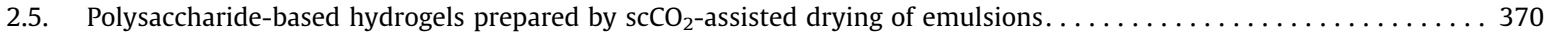

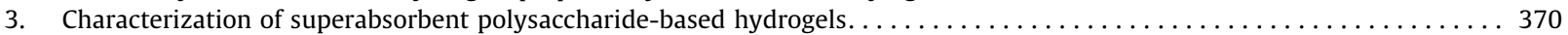

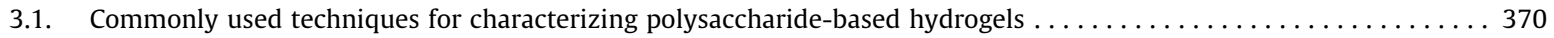

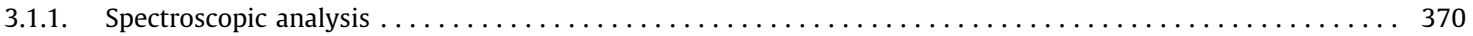

3.1.2. Scanning electron microscopy (SEM) and transmission electron microscopy (TEM) $\ldots \ldots \ldots \ldots$

3.1.3. Elastic modulus $(E)$ of hydrogel through compress/stretch essays $\ldots \ldots \ldots \ldots \ldots \ldots \ldots \ldots \ldots \ldots \ldots$

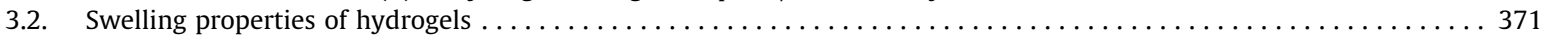

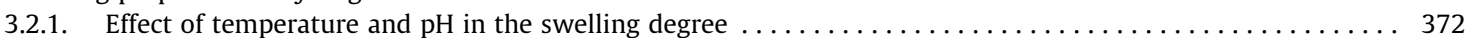

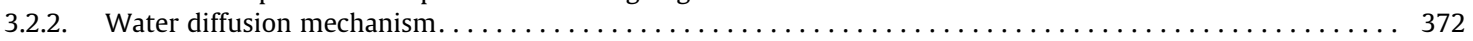

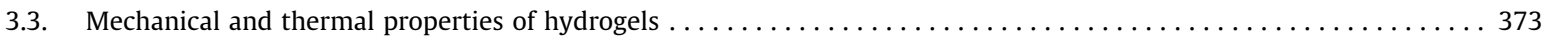

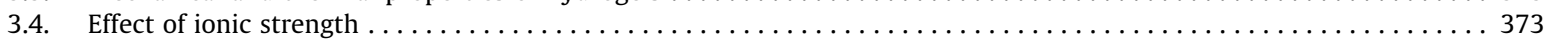

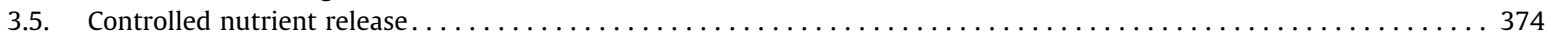

3.5.1. Mathematical models for treating nutrient release profiles data $\ldots \ldots \ldots \ldots \ldots \ldots \ldots \ldots \ldots$

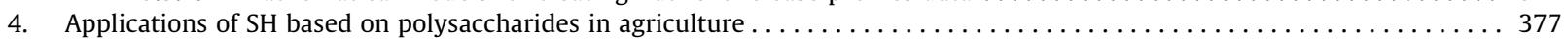

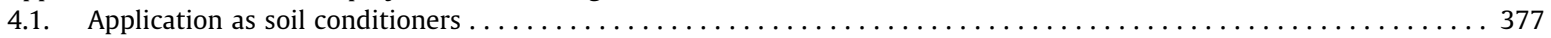

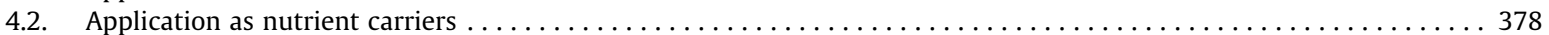

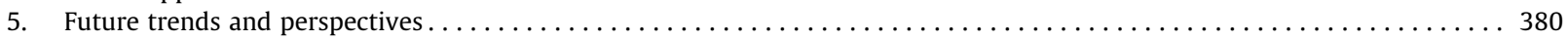

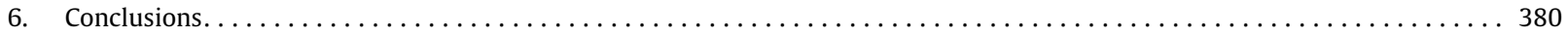

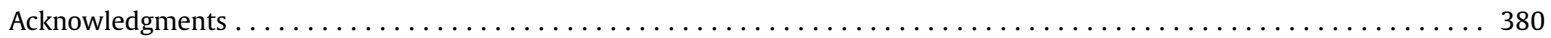

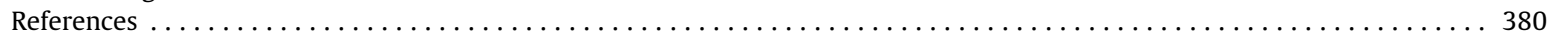

\section{Introduction}

Materials are the basis of any civilization. Due to their availability the development of new technologies and the expansion of science borders are possible. The continuous claim for novel materials has stimulated studies with the most varied range of chemicals and compounds. In this sense, polymers technology has provided a massive contribution to development and design of original materials. Different technological fields, such as medicine [1,2], engineering [3,4], and agriculture [5,6], for instance, have employed polymeric materials. This is stimulated by the polymer advantages over the conventional feedstock. In general lines, polymers are easily processed and chemically modified. They show desirable physical and mechanical properties, and in some cases economically accessible. Among the more promising polymeric materials, a special class of soft materials has attracted wide interest in the last three decades: the hydrogels. The hydrogel preparation was firstly reported in the end of 60s by Witchterle and Lim [7] and since then these incredible materials have been used as powerful tools in different technological segments. A huge number of articles related to hydrogels are reported in literature in which different preparations allowing a myriad of structures, properties and applications are described. This review is devoted to discuss recent studies on superabsorbent hydrogels matrices $(\mathrm{SH})$ based on polysaccharides applied in agriculture as soil conditioners and as nutrient carriers.

\subsection{Basic concepts on superabsorbent hydrogels (SH)}

Typically, superabsorbent hydrogels (SH) are three-dimensional matrix (3D) constituted by linear (or branched) hydrophilic polymers that are chemical of physical crosslinked, with the ability to absorb large quantities (swelling ratio $(S R)>100$ ) of water or biological fluids $[8,9]$. Further, SH can keep their network stable even in the swollen state. Such characteristics result from the crosslinked structure, which assures to SH stability in different media and environments [9]. The crosslinking can be achieved through two main pathways: chemically or physically processes. The chemically crosslinked SH show as main characteristic the irreversible covalent bonds formed among the polymeric chains [10]. A great variety of methods to form crosslinking have indeed been used to prepare chemical hydrogels (e.g. radical polymerization, reaction of complementary groups, grafting reactions, enzymes, etc.) [10]. On the other hand, on physically crosslinked hydrogels the polymeric chains hold together by physical interactions, such as electrostatic interactions, Van der Waals forces and $\mathrm{H}$-bonds [11]. In the last type of hydrogels, the crosslinking is reversible and the matrix can be destroyed as submitted to specific conditions. The crosslinking type used for preparing SH influences also significantly some critical parameters, thus the final properties of $\mathrm{SH}$ and, in consequence, the potential of SH applications [12,13]. Water uptake capacity, swelling kinetic, mechanical and rheological properties, degradation rate, porosity, toxicity, and other properties are intimately 
related to the method used for crosslinking process [12,13]. Therefore, according to the final application, the SH synthesis must be tailored in a certain way allowing to form materials showing (or able to show) desirable responses, e.g. fast swelling, degradability, porosity, etc. Of course, other parameters could be also achieved to assure specific properties. The polymer type, for example, can enhance the hydrophilicity of the SH matrix and contributes to its (bio) degradability. Acrylic monomers/polymers had been often chosen as raw materials to form high performance SH [14]. For years, polyacrylamide, poly(acrylic acid), and other polyacrylates have been extensively applied to prepare high performance superabsorbent materials [15-17]. Currently, the growing environmental concerns have stimulated the use of free oil-based polymers. Alternatively, natural polymers, especially the polysaccharides, have been largely used to replace (or be combined with) those polymers [18-20]. Attractive issues such as low-cost, abundance, renewability, and biodegradability, among others, have stimulated the use of polysaccharides, such as pectin, cashew gum, Arabic gum, starch, chitosan, chitin and others, to design novel SH, which have been applied in the environmental (e.g. agriculture, waste-water treatment, etc.) and biotechnological fields [18-20].

The use of some specific monomers (or polymers) in SH synthesis allows obtaining stimuli-responsive materials able to give different responses according to the medium conditions. Stimuli-responsive SH are those which experience changes either in structure or in other chemical and chemical properties under the influence of environmental (external) conditions such as temperature, $\mathrm{pH}$, light, electric field, and certain chemicals [21,22]. For instance, SH based on the thermoresponsive polymers poly(N-isopropylacrylamide) or poly( $N, N$-diethylacrylamide) can show hydrophilic or hydrophobic behavior [23,24]. Stimuli-responsive SH belong to one of the most exciting and immerging class of smart soft materials [25]. Copolymerizing acrylate monomers and polysaccharides is a versatile option for joining the properties of both. Also other versatility on SH can be achieved associating with another class of compounds/substances, which results in a SH composite [26]. Inorganic particles, whiskers and fibrils, in macro, micro or nanosized dimensional scale, have been incorporated into SH formulations resulting a huge number of original (nano)composite materials [15,27]. The association between polymeric matrix and inorganic/organic particles confers to the composite material enhanced properties or even creates new ones (e.g. biocompatibility, biodegradability, antimicrobial, etc.). Different works have been proposed for preparating SH composites able to overcome some limitations inherent to their use. As consequence, the frontiers of applicability of such materials have been expanded considerably.

\subsection{Some properties of $\mathrm{SH}$}

As earlier mentioned, the main characteristic of SH is their ability to absorb and retain large amounts of aqueous solution. Whereas conventional absorbent materials can absorb up to hundred times their dry weight, SH increase these feature up to thousand times. Guilherme et al. [28] prepared an SH based on chemically modified cashew-gum copolymerized with acrylamide (AAm) monomers producing material labeled as CG-Co-AAm with water uptake capacity equal to 1500, after further partial hydrolysis of acrylamide repeat units. Such interesting ability can be credited to the thermodynamic compatibility between water molecules and the chemical groups that form the SH network [29,30]. In the most part of the cases such materials present electrical charged (or chargeable) groups, which at the initial step of swelling process promote interactions with water molecules by electrostatic (ion-dipole) interactions. At the same time, the hydrophobic moieties into SH matrix interact with water by weak forces. Free water diffuses by osmosis inward the SH matrix after that all the hydrophilic and hydrophobic sites had been filled by water molecules. The water molecules occupy all the available empty spaces existing in the 3D network. For this reason, porosity, density of polymer chains and crosslinking degree are, among others, crucial parameters to the SH water uptake capacity $[29,30]$.

The characterization of the water uptake capacity is undoubtedly primordial to understand the SH structure and potential properties. Swelling assays are mandatory for works discussing SH synthesis and properties. Such assays can be carried out in the most varied conditions (water, saline solutions, buffers, simulated body fluid, etc.), time intervals, and in the presence or absence of external factors such as light, magnetic or electric field, enzymes and solutes [31-33]. The complete elucidation of the swelling profile exhibited by a given SH assures better applicability and adequate responses in specific situations.

Considering the water uptake capacity, the most important feature of $\mathrm{SH}$, is far to be unusual some works make use of different tools (synthesis techniques, factorial designs and response surface methodology, etc.) to optimize procedures and to join into a same SH matrix desirable swelling response and others physical-chemical properties. Different works discuss very original options to form and to improve SH networks. Chemical modifications (grafting and substitution reactions, hydrolysis, etc.) for incorporating different classes of materials/molecules into SH formulation are good examples. Different techniques can be applied to characterize SH network taking into account the method applied to form the 3D matrix, or to chemically modify the parent polymers before the crosslinking process. Spectroscopic techniques, such as NMR, FTIR, RAMAN and UV-Vis are, in general, unanimous candidates to characterize chemical modifying reactions and physical interactions in SH network [29,30] as well some incorporated material (filler) during the gelling process [34,35]. In respect of this, the arrangement of the polymeric chains and filler materials into the SH matrix has been evaluated by X-ray diffraction analysis, which can be carried out in small (SAXS) or wide (WAXS) angle scattering modes [36]. SAXS patterns are very important to elucidate changes in the crystallinity profile of nanoclays incorporated into SH matrices, for instance [37]. Thermal analysis (Thermogravimetry - TGA, Differential Scanning Calorimetry - DSC, and Differential Thermal Analysis - DTA) have been employed to evaluated, as pointed out above, the interactions between the SH network and the water, the thermal stability, and to determinate some properties (melting, $T_{m}$; and glass transition, $T_{g}$; temperatures) $[38,39]$. The morphological aspects 
of SH, which stands as key role in uptake capacity and swelling kinetics, have been investigated by microscopy (Atomic Force Microscopy - AFM, Scanning Electron Microscopy - SEM, and Transmission Electron Microscopy - TEM). Images recorded by SEM from surfaces (fractured or not) regions of different SH matrices are powerful tools to evaluate aspects as pore size and pores size distribution [40]. On the other hand, TEM images allow qualitative understanding of internal structure as well the particles distribution/formation within the SH composites matrices [41]. Despite of all these considerations about the morphological aspects, it is worthy to say that SH often presented fast swelling capability and such property is independent on the size of SH [16]. Unlike microstructure and morphology, which affect the SH water uptake capacity, mechanical and rheological properties are sensitive to the swollen state. In certain cases, high swelling degrees cause significant harm on the mechanical properties [42]. As mentioned, the capacity of SH for absorbing water contributes significantly for water retention and maintaining some properties of soil such as local humidity [43], increase the soil permeability and aerating helping the increase of nitrogen retained by the plant [44]. One very important drawback of highly swollen SH is the poor mechanical properties. As higher is the amount of water within hydrogel poor the mechanical properties [16]. Some works are devoted to investigate strategies to overcome this limitation and one of the most prominent advances in this area reports the use of fillers (nanowhiskers, nanofibrils, etc.) as reinforcement agents $[15,45,46]$. This approach ensures good balance between high swelling and adequate mechanical properties. Attempts for deep discussion about the design and the current methods for synthesizing/characterizing SH matrices applied in agriculture are made in next sections, mainly focused on SH based on polysaccharides.

\section{Preparation of superabsorbent hydrogels based on polysaccharides}

\subsection{Chemical modification of polysaccharides towards hydrogel formation}

In recent years, SH incorporating polysaccharides have been widely studied [47-49], because they appear as viable ecologic and economically alternatives, aiming at soil conditioning [50]. Other characteristics which have been assigned for the use of polysaccharide-based SH are their nontoxicity, biodegradability, availability, and efficiency of application [51]. The polysaccharides are used in hydrogels field as a constituent-key, serving as a support on polymer network and allowing other properties such as (bio)degradability. In other words, if the polysaccharide chains break, the hydrogel unmakes. This characteristic makes the polysaccharide-based hydrogels appropriate for uses in soils as a fully biodegradable system for controlled release of nutrients, because the polysaccharides are susceptible to (bio)degradation by microorganisms [52] or chemical or physical stimulus [53]. If, for one side, the degradability of polysaccharide avoids the contamination of soil by chemicals, on the other side it originates a drawback that needs be overcame. For instance, SH based on polysaccharide may present precocity in degradation in such a way that the nutrients inside the 3D matrix is not released much slow as requested [16]. In the best situation, the total amount of nutrients should be released in a rate compatible to the plant necessity and occurring in the total range of degradation time of $\mathrm{SH}$ matrix.

The polysaccharides in their native form are not able to produce hydrogels with good stability, which is an essential condition for uses as controlled system of nutrients into soil. Hydrogels from polysaccharides may be prepared using chemical or physical crosslinking approach or both [54-58]. The advantage of chemicals approach (crosslinking through covalent bonds) is that the 3D matrix remains stable with time, preserving the gel properties. To address the challenges associated with the lack to ability to produce mechanically stable hydrogels from not chemically modified polysaccharides, an approach based on a chemical reaction that involves linking carbon-carbon double bonds to polysaccharide chains has been widely used [59]. Many polysaccharides, including those of complex structures, such as pectin [60], cashew gum [28], Arabic gum [61] and starch [62], have been modified through vinyl groups incorporation in order to produce SH. The idea of modifying polysaccharides by addition of vinyl groups is far being new, although the mechanisms involving methacrylate addition reaction through glycidyl methacrylate (GMA) were recently clarified. This approach was pioneered by van Dijk-Wolthuis et al. $[63,64]$ in the mild-1990s. More recently a paper devoted to clarify such mechanisms was published [65].

\subsection{Chemical hydrogels based on different vinyl-modified polysaccharides through addition of methacrylate groups}

\subsubsection{Pectin}

The chemical modification of pectin has been shown to be an efficient strategy using polysaccharides as starting polyfunctional moieties to create a SH [60]. The swelling profiles of modified pectin-based SH in saline solutions were in same order magnitude of those found in distilled water, i.e., they interestingly do not lose their capacity of water superabsorption in the presence of salt in certain conditions. Those hydrogels also showed controlled release characteristics of urea, phosphate and potassium [60].

The modification of polysaccharides with the use of the GMA occurs by transesterification and/or epoxide ring-opening reaction mechanisms [66,67]. The occurrence of one or both of the reaction mechanisms depends on $\mathrm{pH}$ and chemical nature of polymer and solvent. At acidic medium, GMA reacts with both carboxylic and hydroxyl groups by epoxide ring-opening mechanism in a forward and irreversible reaction route [67]. The reaction resultant products of epoxide ring-opening reaction are two isomers: 3-methacryloyl-1-glyceryl and methacryloyl-2-glyceryl esters of polysaccharide. At basic condition, GMA reacts with hydroxyl groups by both the transterification, which occurs in the forward and reverse direction, and 
the epoxide ring-opening. Under this condition, the following isomers are formed: vinyl methacrylate of polysaccharide, 3methacryloyl-1-glyceryl ether of polysaccharide, and 3-methacryloyl-2-glyceryl ether of polysaccharide [65].

\subsubsection{Cashew gum}

An effective SH was prepared using chemically modified cashew gum copolymerized with acrylamide and submitted to further hydrolysis [28]. The cashew gum was firstly modified with GMA using a mixture of water and dimethyl sulfoxide (DMSO), as solvent, and $N, N, N^{\prime}, N^{\prime}$-tetramethylethylenediamine (TEMED), as catalyst. Depending on the reaction time used for acrylamide hydrolysis, the cashew gum hydrogel can swell in water up to about 1500 times its own dry weight, without significant loose the geometrical form as compared to original material (dry material). That hydrogel is a high performance water absorbent, which makes it attractive for soil conditioning [28], but the problem was the use of DMSO as solvent for chemical modifying the polysaccharide. The work of Reis et al. [65] is an alternative avoiding use of DMSO.

\subsubsection{Starch}

Starch is among the most widely used polysaccharides in SH production, and has been the target of several studies including industrial and academic sectors [68]. It is the second most abundant carbohydrate polymer in nature (next to cellulose) and stands out as one of the most important natural polymers. Beyond being obtained from renewable sources, this polysaccharide offers other important advantages such as low cost, ease of chemical modification, ability to replace some synthetic polymers, good mechanical resistance and plasticity. The modification of starch with GMA has been commonly processed in the presence of catalytic agents such as 4 -( $N, N$-dimethylamino)pyridine (DMAP) and $N, N, N^{\prime}, N^{\prime}$-tetramethylethylenediamine (TEMED). The product resultant from that reaction was able to undergo radical reaction that leads to hydrogelation. Chemical starch hydrogels of high water absorption capacity were prepared through ultrasound-assisted radical crosslinking/polymerization reaction in the presence of acrylamide and acrylic acid. The as-obtained material was able to absorb approximately $150 \mathrm{~g}$ of water per gram of dry hydrogel after $200 \mathrm{~min}$ of immersion [62].

\subsubsection{Arabic gum}

Arabic gum was also successfully modified with GMA [34]. From then on, the use of potentially toxic reactants and of organic solvents in the modification reaction was discontinued. Vinylated Arabic gum was obtained by an adapted approach that uses water as solvent without catalytic agent. However, when only water is used as solvent, a further problem had to be overcomed: GMA is insoluble in water. To address the challenges related to insolubility of the GMA in the reaction medium, a heterogeneous phase system composed of water-soluble Arabic gum and water-insoluble GMA was provided using high stirring speed at a temperature range of $60-65{ }^{\circ} \mathrm{C}$. Under these conditions, the polysaccharide is able to be vinyl-modified at the interface of the GMA-water system. The product was easily crosslinked through reaction with acrylamide and sodium acrylate monomers, forming SH. It absorbs ca. $500 \mathrm{~g}$ of water per gram of dry hydrogel in $60 \mathrm{~min}$, without its mechanical stability being seriously affected [34].

\subsection{Chemical hydrogels based on polysaccharides vinyl-modified by redox reaction}

Thermal treatment of the material in the presence of peroxides, which leads to formation of radical ions on hydroxyl or carboxyl groups, is also an efficient approach to transform uncrosslinked polysaccharides into a hydrogel. In such a case, covalent crosslinks can be introduced by adding vinyl monomers that reacts with the radical hydroxyl groups of the polysaccharide. For instance, Diao et al. [69] modified peanut hull cellulose using potassium persufate at $50{ }^{\circ} \mathrm{C}$ and the product from that reaction was further polymerized with acrylic acid, acrylamide, 2-acrylamide-2-methyl-1-propanesulfonic acid producing SH. The process to convert the uncrosslinkable polysaccharide into a functionalized/crosslinked polymer starts off with the thermal decomposition of the potassium persulfate. At temperatures close to $85^{\circ} \mathrm{C}$ or above, the potassium persulfate undergoes homolytic cleavage forming sulfate radical ions. After the breakdown of the peroxide, the radical reacts with oxygen of sulfate or hydroxyl groups in carbohydrate. Then the new formed radical reacts with vinyl monomers in the same manner as the sulfate radical ions did. It follows that there is an addition of more and more monomers to the ever-increasing chain. Equivalent approaches have been used to modify kappa-carrageenan [9], carboxymethyl cellulose [70], sodium alginate [71], xanthan gum [72], carboxymethyl chitosan [73], chitosan [46] and so forth.

The production of SH based on chitosan has significantly increased in recent years [74-77]. Chitosan can be modified through reaction with vinyl monomers [78,79], compounding with functionalized components [80], and complexation with polyelectrolytes [81].

\subsection{Physically (non covalent) hydrogels based on polysaccharides}

Another approach that has been explored involves introducing physical crosslinks to prepare noncovalent hydrogels. In this direction, carboxymethyl cellulose was obtained through the carboxylation reaction of cellulose with monochloroacetic acid in hydroxide solution. The product from that reaction is a polyelectrolyte that can be physically (ionically) crosslinked with multivalent metal ions such as aluminum. There are natural anionic polysaccharides with ability to form strong hydrogels with divalent and trivalent cations, although divalent ions cause contraction of polymer network (during crosslinking process) affecting the water absorption capacity. On the other hand, these hydrogels can be readily transformed 
to aerogel by scCO $\mathrm{SCO}_{2}$-assisted drying [82]. The aerogel possesses highly porous polymeric network with connected pathways throughout the material. This type of architecture allows fast water diffusion into and through the hydrogel.

\subsubsection{Polysaccharide-based hydrogels prepared by emulsion technology}

Particulate SH can also be produced through crosslinking/polymerization emulsion process. Although the polysaccharides have no good sphere-forming capacity, because of complexity of their macromolecular fragments and structural-conformational characteristics, this approach provides particles with spherical shapes, as a result of minimum single-particle surface energy [83]. Emulsion polymerization offers advantages for simple, easy and quick preparation; products with high molecular weight [70]; and well-defined preparation stages. The stability of an emulsion is related both to chemical nature of interfacial film and to attraction/repulsion balance force occurring among the particles suspended in the liquid, which are important in the prevention of the droplets coalescence [83]. An efficient strategy to prepare crosslinked polysaccharide particles with controlled size is the crosslinking/polymerization in a water-in-oil emulsion under vigorous stirring [84]. In such a case, the spherical structures results of a random movement of water droplets inwards the oil phase under vigorous stirring. Under these conditions, stable emulsion of oil phase-surrounded water droplets with controlled size within a certain range is formed. The reaction occurs within the small water droplets due to hydrophilicity of the reactants. The water-inoil can be stabilized by amphiphilic substances such as poly(vinyl alcohol) (PVA), an emulsifying agent. The adsorbed PVA on interface reduces the interfacial tension. Ultrasound-assisted polymerization has also been an excellent tool in the production of hydrogel particles with defined outlines [85]. The main advantage of such an approach is that the crosslinked polysaccharide particles are formed in few seconds. On the other hand, reactions that require polymerization times longer than 3-5 min can cause thermal degradation of the polysaccharide, owing to an overheating of the emulsion [85]. In such a case, polymerizations at room temperature under the protection of $\mathrm{N}_{2}$ atmosphere should be considered, if possible.

\subsection{Polysaccharide-based hydrogels prepared by $\mathrm{scCO}_{2}$-assisted drying of emulsions}

The water absorption capacity of hydrogel particles can be improved by increasing their porosity. A way of doing this is to dry the particles in $\mathrm{scCO}_{2}[69,86]$. Beyond providing porous particles, supercritical drying also is an efficient approach to prepare small particles with narrow particle size distribution, as compared to traditional solvent evaporation of emulsions used in the production of polymeric nanoparticles [87]. In $\mathrm{scCO}_{2}$, the original configurations of the polymer chains are kept owing to a fast removal of solvents from emulsion by the solubilization in the $\mathrm{scCO}_{2}$ phase. In the most elementary form, $\mathrm{CO}_{2}$ dissolves into the liquid droplets generated by the collapse of stream of the liquid and the solvent evaporates in the $\mathrm{scCO}_{2}$ phase. In the supercritical environment, the pressure is equal in all directions around a particle, providing more defined shapes.

\section{Characterization of superabsorbent polysaccharide-based hydrogels}

\subsection{Commonly used techniques for characterizing polysaccharide-based hydrogels}

\subsubsection{Spectroscopic analysis}

Important insights into structural characterization of polysaccharides can be gained by Fourier transform infrared spectroscopy (FTIR). This tool allows us to observe changes in the modified polymer for further identification and quantification $[88,89]$. The analysis is performed by the observation of spectral alterations (in the modes of vibration) of the unmodified polymer, chemically-modified polymer and final products such as the hydrogels. Because of the FITR data are readily obtained, this analysis could be the initial study of whole process. The results can be complemented by nuclear magnetic resonance (NMR), which gives additional data for a more detailed analysis of the chemically modified structures from a molecular point of view. Furthermore, NMR spectroscopy provides an important tool for accomplishing the modification reaction. In the case of reaction kinetics, ${ }^{1} \mathrm{H}$ NMR is more appropriate than ${ }^{13} \mathrm{C}$ NMR, because it provides faster spectral data acquisition [9]. ${ }^{13} \mathrm{C}$ NMR is useful for polysaccharides modified with GMA since it gives an overview of the gelation by ${ }^{13} \mathrm{C}$ resonances of the methacrylate conjugation [90].

\subsubsection{Scanning electron microscopy (SEM) and transmission electron microscopy (TEM)}

SEM data give important insights on morphological properties of hydrogels such as porosity, sample shape and surface changes. However, to obtain information on actual morphology of a hydrogel, the analysis depends on preparation of the sample in specific conditions. A convenient route to prepare the sample prior to SEM imaging is the freeze-drying of hydrogel swelled to equilibrium in water or aqueous solution. In practical terms, the swollen hydrogels are withdrawn from swelling environment and quickly frozen by immersion in liquid nitrogen before being lyophilized. Under these conditions, it is supposed that the morphology of the swollen hydrogels is maintained [91].

When a hydrogel is analyzed by bright field TEM imaging, the electron beam goes through the sample without causing any affect in shorter analyze times. Difficult in scattering electrons will occur ever the sample is formed by light atoms. Although few morphological features can be identified, TEM images did not showed clear details of the sample. Attempts 
can be made to create high contrast images by changing the bright field microscope into a dark field microscope [92]. In some cases, samples made of polyelectrolyte networks can show small details, owing to crystalline regions.

\subsubsection{Elastic modulus (E) of hydrogel through compress/stretch essays}

The elastic modulus gives relevant information, with excellent quality and reproducibility, for development of hydrogels. Several techniques can be used to obtain the value of $E$. such determination can be done, for instance, from the curves of stress vs. strain by fitting the experimental data to Eq. (1) [93-95].

$$
\sigma=\frac{F}{A}=E \varepsilon
$$

where $F$ is the force and $A$ is the cross-sectional area of the hydrogel, $E$ is the elastic modulus, and $\varepsilon$ is relative deformation of the sample $\left(\varepsilon=\Delta l / l_{0}, \Delta l\right.$ is the extent of deformation and $l_{0}$ is the initial length of sample in direction to uniaxial deformation). The data are obtained by measuring the force necessary to compress/stretch the hydrogel up to a defined deformation extent. Correlation stress and strain when the hydrogel undergoes mechanical compressions under elastic deformation can be used for such determination. In such a case, the strain is recovered by removing the applied stress. From a physical-chemical point of view, it is said that the stress is accommodated by the rearrangement of the polymer chains within the hydrogel. As a consequence, retractive elastic forces concomitantly are developed in those polymer chains owing to their tendency to return to original configuration [96].

\subsection{Swelling properties of hydrogels}

Chemical SH are formed of hydrophilic 3D networks of covalently crosslinked polymers (e.g. owing to crosslinking points), such structures are insoluble and, depending on the used monomers during the synthesis, they may have satisfactory mechanical resistance [97]. Nevertheless, the higher the amount of crosslinking points the lower the swelling degree [98]. In view of this, an appropriate crosslinking control is needed during the synthesis of chemical SH used in agriculture, as for controlled nutrient release or soil conditioning [99].

The equilibrium swelling theory of Flory and Rehner [100] describes the equilibrium swelling of a lightly crosslinked polymer in terms of crosslink density and the quality of the solvent through the following equation [100]

$$
-\left[\ln \left(1-v_{2}\right)+v_{2}+\chi_{1} v_{2}^{2}\right]=\frac{V_{1}}{\bar{v} M_{c}}\left(1-\frac{2 M_{c}}{M}\right)\left(v_{2}^{\frac{1}{3}}-\frac{v_{2}}{2}\right)
$$

where $V_{1}$ is the molar volume of solvent and $v_{2}$ is the volume fraction of polymer in the matrix, $\chi_{1}$ is the Flory solvent-polymer interaction parameter, $\bar{v}$ is the specific volume of the polymer, $M$ is the primary molecular weight of polymer (before the crosslinking process) and $M_{c}$ is $s$ the average molecular mass between crosslinks or the network parameter.

The swelling of a chemical hydrogel after being added into either water or a specific solute solution results of a diffusion process involving the solvent molecules inwards the 3D matrix due to the hydrophilicity causing expansion of polymeric chains, counterbalanced by an elastic retractive energy upon stretching of the polymeric chains [101-104]. The 3D network expansion increases the average distance between crosslinking points. As a result, electrostatic repulsions among either the anionic or the cationic groups present in the polymeric segments are intensified [105], which drives the diffusion process of the solute into hydrogel network. The osmotic force is counterbalanced by elastic retractive forces [32,106,107]. While the volume expansion of an unconstrained polymer sample is isotropic, the surface-attached polymer networks of hydrogels are free to swell only perpendicularly to the substrate [102]. In the most technical applications, the swelling of polymers and hydrogels are considered as a detrimental effect [108]. However, the polymeric swelling is extremely useful for applications of a hydrogel at controlled agricultural nutrient release and soil conditioning $[108,109]$.

The swelling degree $(S D)$, or the swelling ratio $(S R)$, for a hydrogel may be calculated according to Eq. (3):

$$
S D=S R=\frac{m_{\text {swollen }}-m_{\text {dry }}}{m_{\text {dry }}}
$$

in which $m_{\text {swollen }}$ and $m_{\text {dry }}$ are the masses of swollen and dried hydrogels, respectively.

Eq. (3) for the swelling degree is analogous to engineering strain in mechanical testing [97,110]. A better definition for swelling degree that parallels the integral expression of true strain in mechanical tests is given by Eq. (4):

$$
S D_{\text {true }}=\int_{m_{\text {dry }}}^{m_{\text {swollen }}} \frac{d m}{m}=\ln \left\{\frac{m_{\text {swollen }}}{m_{\text {dry }}}\right\}=\ln \left\{\frac{m_{\text {dry }}+\Delta m}{m_{\text {dry }}}\right\}=\ln \left\{1+\frac{\Delta m}{m_{\text {dry }}}\right\}=\frac{\Delta m}{m_{\text {dry }}}-\frac{1}{2 !} \ln \left\{\frac{\Delta m}{m_{\text {dry }}}\right\}^{2}+\cdots
$$

Eq. (4) for the "engineering degree of swelling" is valid if $\Delta m / m_{d r y}$ is small enough that the quadratic term is negligible in comparison to the linear term in Eq. (4). For swelling degree greater than $100 \%$ (i.e., $S D>1$ ), $S D_{\text {true }}$ in Eq. (4) is most likely a better representation of the swelling degree than $S D$ in Eq. (3) [97,110].

The swelling degree can also be measured according to the Japanese Industrial Standard (JIS) K7223. The dry hydrogel is immersed in deionized water for $16 \mathrm{~h}$ at room temperature. After swelling, the hydrogel is filtered using a stainless-steel net of 100-mesh $(149 \mu \mathrm{m})$ and the swelling degree calculated by Eq. (5) [111]. 


$$
S D(\%)=\frac{M_{d}}{M_{\text {ins }}} \times 100
$$

in which $M_{d}$ and $M_{i n s}$ are the masses of dried hydrogel and of the insoluble portion after extraction with water, respectively.

The efficiency of loading solutes in hydrogels as a function of time, during the swelling process, may be calculated from Eq. (6):

$$
\text { Efficiency of loading }(t)(\text { in } \%)=\frac{\text { solute }(t=0)-\text { solute }(t)}{\text { solute }(t=0)} \times 100
$$

in which solute $(t=0)$ is the initial concentration of solute in supernatant prior to the contact with hydrogel, and solute $(t)$ is the residual concentration of solute in the supernatant after a time $t$ in contact with hydrogel.

\subsubsection{Effect of temperature and $\mathrm{pH}$ in the swelling degree}

Greater hydrogel swelling occurs at higher temperatures due to a combination of the following factors: (i) network thermal expansion, and (ii) destabilization of network junctions, causing expansion of the matrix after water diffuses into the porous structure [112,113]. When the swelling is conducted in acidic media, the 3D hydrogel network may be destabilized $[97,112]$. In acidic media (with $\mathrm{pH}<\mathrm{p} K_{\mathrm{a}}$ ) the "protonation" of anionic groups of hydrogel networks increases, decreasing the concentration anionic groups. It lowers the electrostatic repulsion among these anions on the same chain or on different chains. Furthermore, equilibrium swelling occurs at shorter diffusion times when pH decreases [97]. In basic media, the concentration of anionic groups increases relatively, and electrostatic repulsion causes chain expansion as well as macroscopic expansion of $\mathrm{SH}$ as observed in Fig. 1.

As a result, the rate of mass transfer of neutral organic and inorganic solutes into the porous matrix increases. SH which the water uptake curves are shown (Fig. 1a) and photo in swollen state (Fig. 1b) was used for removing methylene blue from aqueous solution with very high efficiency [97].

\subsubsection{Water diffusion mechanism}

The diffusion of water into polymeric hydrogel networks has been studied using the more general version of the power law equation, in which the exponent $n$ is a parameter that describes the diffusion mechanism of water [114]. For water diffusion into hydrogels, values of dimensionless $n$ exponent are frequently calculated from the $\log -\log s$ lope of $M_{t} / M_{e q} v s$ immersion time $(t)$, as described by Eq. (7)

$$
\frac{M_{t}}{M_{e q}}=k t^{n}
$$

in which $M_{t}$ and $M_{e q}$ are the masses of water absorbed by hydrogel at specific immersion time $t$ and at equilibrium condition, respectively, being the dimensionless $k$ proportional to the diffusivity of water into the polymeric network [32]. Eq. (7) is a more general version of the power law equation. It is applied when both time-lag and bust effects are null.

The values of $n$ are commonly characterized using Fickian diffusion, non-Fickian diffusion (anomalous) and Super Case II. For $n<0.5$, the water transport is characterized by Fickian release. In this case, water molecules are considered to diffuse through the polymer networks simply through diffusion processes. For $0.45 \leqslant n \leqslant 0.89$, water diffusion is characterized by non-Fickian diffusion. In this case, the transport mechanism can be characterized by two processes occurring
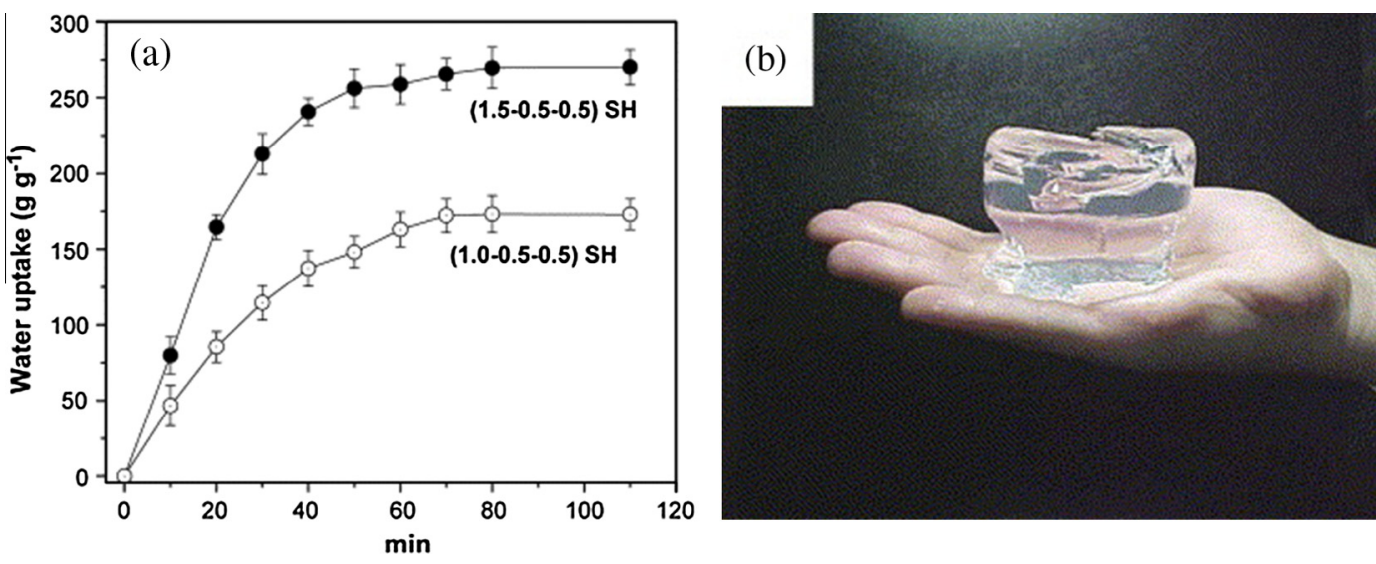

Fig. 1. (a) Water uptake capacity for (1.5-0.5-0.5) and (1.0-0.5-0.5) SH as a function of immersion time in water. (b) Picture of (1.5-0.5-0.5) SH swollen 275 -fold from its own dry weight. Data of water uptake were calculated as the average over the three water uptakes weighed. Error bars represent standard deviations for the three experiments. The used label indicates the composition (in $\mathrm{g} \mathrm{mL}^{-1}$ ) of (chemically modified Arabic gum-AAm-NaAAc) in the SH synthesis. Reprinted with permission from Ref. [105]. Copyright 2006 - Elsevier. 
simultaneously - diffusion through the pores and macromolecular relaxation of the hydrogel network. When the phenomenon of macromolecular relaxation is involved, there is a direct relationship with the flexibility of the polymer chains of SH with water transport. Finally, for $n>0.89$, the diffusion mechanism of water is exclusively governed by macromolecular relaxation, i.e., Super Case II [32,114]. The Fickian diffusion models set that the diffusion of water into hydrogel networks takes place until 70\% from the initial absorption. Above 70\%, there is no linearity in the $\log -\log$ slope of $M_{t} / M_{e q}$ vs. time $(t)$. The linear regression of Eq. (7) is seen in Eq. (8):

$$
\log \left(\frac{M_{t}}{M_{e q}}\right)=\log K+n \log (t)
$$

\subsection{Mechanical and thermal properties of hydrogels}

Chemically crosslinked hydrogels, based on biopolymers such as polysaccharides, proteins, and amino acids, have been extensively studied for medical, pharmaceutical, and biological applications due to their biocompatibility with living organisms, biodegradability, accessibility, and renewability [115-117]. However, most synthetic chemical hydrogels possess low mechanical strength, poor toughness, and limited extensibility and recoverability. These problems are caused by their intrinsic structural heterogeneity and lack of efficient energy-dissipation mechanisms which limit their extensive use for practical applications [118]. In many cases, the thermal and mechanical stability of these hydrogels need to be firstly improved before the practical application [95,97,119-121]. Problems associated with poor thermal and mechanical stability may be addressed via the incorporation of specific crosslinkers and inorganic nanoparticles during hydrogel synthesis [97], from the synthesis of double-network [122], slide-ring, [123], nanocomposite [15], triblock copolymer hydrogels [122], and with pH-based responsive hydrogels [124].

Many polymeric systems like those formed by hydrogels exhibit behavior combining elastic and viscous properties, commonly termed as viscoelastic hydrogels $[125,126]$. The mechanical behavior of ideal solids is mathematically described by Hooke's law, which states that the strain of a sample is directly proportional to the applied stress. Thereunto, the proportionality constant is referred as being the Young's modulus $[125,126]$. Newton proposed that the applied stress is proportional to the strain rate, and the proportionality constant is, in this case, referred as being the liquid viscosity. Therefore, the response of ideal liquids to an applied stress is time and strain rate dependent $[125,126]$.

In order to characterize the mechanical and thermal properties of viscoelastic hydrogels, dynamic mechanical analysis can be applied [127]. This is an analytical technique in which an oscillating stress is applied to a sample and the resultant strain is measured as functions of both oscillatory frequency and temperature [128]. From this, a comprehensive knowledge of the relationships between the various viscoelastic parameters such as storage and loss module, mechanical damping parameter, dynamic viscosity, and temperature may be obtained [127]. Dynamic mechanical methods have been successfully employed to characterize the thermo-rheological properties of hydrogels [127-130].

As already mentioned, thermal and mechanical properties of hydrogels may be characterized respectively by differential scanning calorimetry (DSC) and compression testes [129]. DSC testes in SH are based on the assumption that only free water may be frozen. Then, it is assumed that the measured endotherm when the frozen swollen hydrogel is warmed represents the melting of the free water, and this value will yield the amount of free water in the hydrogel sample being tested. The bound water is then obtained by difference of the measured total water content of the hydrogel test specimen (gravimetric), and the calculated free water content by DSC [29].

\subsection{Effect of ionic strength}

The swelling of porous hydrogel occurs due to water and inorganic/organic solutes diffusion into polymer networks through capillarity associated to physical interactions [104]. Water molecules and solutes are absorbed due to interactions with hydrophilic groups such as caboxylates and amines, forming hydrogen and covalent bonds, beyond other physical interactions [131]. The swelling degree can be controlled by the variation of the chemical composition and crosslinking degree of the polymer network, and $\mathrm{pH}$, temperature and ionic strength of swelling solutions $[97,104,110,112,113,121,132-134]$.

The ionic strength of swelling solutions can significantly affect the swelling degree of hydrogels, the adsorption capacity of agricultural nutrients and the controlled nutrient release on soils [135]. The effect of the ionic strength is related to the unbalance of the osmotic pressure and elasticity of hydrogels that occurs during swelling. The osmotic pressure is resulted of the difference between the ion concentrations inside and outside crosslinked polymer hydrogel network [131]. The effect of ions coming from salts in the swelling degree of hydrogels can be evaluated by Eq. (9):

$$
f=1-\left(\frac{S D_{\text {saline }}}{S D_{\text {water }}}\right)
$$

in which $S D_{\text {saline }}$ and $S D_{\text {water }}$ are the equilibrium swelling degrees for saline solutions and pure water, respectively [136]. As close to zero is the value of $f$ for a hydrogel in a certain saline solution lower is the ionic effect of such solution to the swelling degree. When $f$ is close to unity stronger is the saline effect. 
Studies of the swelling degree of crosslinked kaolin/clay-based hydrogel composites were carried out [137]. Higher absorbance of water was observed for hydrogels containing clay and kaolin. It occurred due to higher amount of hydroxyl and carboxyl groups in the hydrogel network. The Donnan equilibrium theory points that as the ionic strength is raised, the distribution in the concentration of mobile ions between the gel and solution is reduced. So, the osmotic swelling pressure of the mobile ions inside the gel decreases and the hydrogel collapses. Once in contact with high ionic strength solutions, the previously loaded-nutrient swollen hydrogels collapses causing decrease in the efficiency on the controlled nutrient release $[137,138]$. Metals coming from salt and present in high ionic strength solutions decrease the swelling degree due to formation of intra- and intermolecular metal complexes with carboxyl, hydroxyl and amine groups of hydrogels. It decreases the electrostatic repulsion among the polymeric networks which is responsible for swelling [139].

The mass of crosslinked hydrogels based on ethylcellulose/poly(acrylic acid-co-acrylamide) increased 134 and 70 times related to the dried weight after be swelled in distilled and tap water, respectively. This shows that the presence of ions in the swelling solution has a profound effect on the absorbency behavior in this type of hydrogel [108]. As mentioned, according to Donnan equilibrium theory, osmotic pressure is the driving force for swelling of electrical charged hydrogels. In tap water, the osmotic pressure difference between water inside the polymeric network and that one in the external solution decreases, resulting in the decrease of the water absorbency. In addition, the penetration of counterions, such as $\mathrm{Na}^{+}$, $\mathrm{Mg}^{2+}$ and $\mathrm{Ca}^{2+}$, present in tap water into the polymeric network makes the screening effect of them on anionic groups (such as $-\mathrm{COO}^{-}$) more evident [140], which also decreases the water absorbency. Furthermore, in the case of tap water with multivalent cations, "ionic crosslinking" at surface of hydrogels causes an appreciable decrease in water absorbency. It has been reported that calcium ions can drastically decrease the swelling capacity for a hydrolyzed starch- and polyacrylonitrilegrafted copolymer, due to the complexing ability of the carboxylate groups, inducing the formation of intra- and intermolecular complexes [140,141]. Then, depending on the chemically SH network, significant effect is observed on absorption capacity of water, and consequently, on the adsorption capacity of agricultural nutrients [142]. Cations from saline solutions compete with nutrient ions by the active sites inside the 3D hydrogel structure [137]. So, it can be pointed out that high ionic strength (solutions solute or other external environment) difficult the application of hydrogels in controlled solute release due to higher possibility of collapse their polymer 3D network [143].

\subsection{Controlled nutrient release}

Controlled nutrient release from biodegradable chemical hydrogels have been widely studied all over the world $[108,133,135,142,144,145]$. Controlled nutrient release from polysaccharide-based SH, as carriers, improved the functional efficiency of nutrients, herbicides, insecticides and fungicides, decreasing the cost of the application process, toxicity for humans and environmental pollution [144]. Therefore, controlled nutrient release systems are one key approach for reducing the nutrient losses by leaching after application, minimizing the associated economic costs and environmental problems [109]. In this approach, controlled nutrient releases based on hydrogels can be used for obtaining optimum release rate for longer periods after only one application [146].

Appropriate bioavailability of water and nutrients on soils are important to the growing and development of plants and cultivars [144]. As consequence, the productibility indexes of vegetables, legumes, cereals and grasses are higher. Soils appropriately prepared for planting should not have organic and inorganic contaminants since they can interfere in the gowning and development of roots, and consequently the whole plant [146]. Herein, some properties need to be controlled and they are important in order to indicate the type of crop more appropriate in that environment. One of the properties that need to be monitored is the quantity of nutrients present in the soil. The most important and essential nutrients for planting soils include potassium, calcium, iron, copper, nitrogen, phosphorus, sulfur and boron [146], although it is estimated that from $40 \%$ to $70 \%$ of nitrogen and $50 \%$ to $70 \%$ of potassium are lost by leaching [147]. Thence, high quantities of nutrient are not absorbed by plant roots [142]. In order to solve this problem, additional doses of nutrients, herbicides, insecticides and fungicides need to be applied. However, this additional application increases the loss of compounds by leaching, exacerbating the environmental pollution. In view of this, superabsorbent chemical hydrogels (often polysaccharide-based) have been studied as controlled release carriers of compounds in soils prepared for planting [147-149].

The fraction of nutrient, herbicide, pesticide or other solute released from chemically crosslinked hydrogels may be calculated according to Eq. $(10)[97,113]$.

$$
\text { Fraction released }\left(F_{R}\right)=\frac{\text { amount released }}{\text { amount loaded }}
$$

The amount loaded can be calculated through Eq. (6).

\subsubsection{Mathematical models for treating nutrient release profiles data}

The vast majority of the superabsorbent materials are used in granular form [83]. Very effective forms and technologies for producing and dosing them have been developed. Granular form often is coated by hydrophilic polymer that helps the first stage of water absorption process and the releasing of loaded nutrients. However, in dried state, SH are hard and brittle, fact that can influence the swelling/release processes. In that follows, discussions related to mechanism and mathematical models for nutrient release from coated granules or from SH are given, focused to agriculture application. 
3.5.1.1. Nutrient release profile from polymer granules. Monitoring released nutrients on soils has attracted attention of many researchers and governments over the world because the water quality for human consumption and animal has been compromised [146]. One of the traditional approaches for analysis and monitoring of agricultural nutrients in natural systems is defined as SFA (Substance Flow Analysis) which consists of an analysis of the total flow of a nutrient or a group of nutrients through a given system during a given time [150]. Since SFA does not provide systematic quantification methods for nutrient release on soils, it is expensive, time-consuming and oversimplified; an extended substance flow analysis (ESFA) may be accomplished [151]. This methodology is based on six-steps: (i) system definition, (ii) model development, (iii) database development, (vi) model validation, (v) results interpretation and (vi) uncertainty analysis [151]. Studies indicate that the dominant contributor for surface water eutrophication and groundwater nitrate enrichment is the uncontrolled release of agricultural nutrients, herbicides and pesticides on soils [152]. Thereby, the main aim of using coated fertilizer granules and crosslinked chemically polysaccharide-based hydrogels in the controlled nutrient release on soils is the decreasing the loss of nutrients by leaching and mitigating environmental problems [153,154].

For many years coated fertilizer granules have been studied for the controlled nutrient release on soils since optimal uptake by plants and crops is always desired, decreasing the cost of production and minimizing the waste and environmental problems [141,149,153,155-157]. The release profiles from coated granules are divided in three main steps: (i) initial stage with no significant nutrient release, (ii) constant release from medium interval of times, and (iii) gradual decay of the release rate from the longer release times $[155,156]$. Based on these three agricultural nutrient release profiles as a function of time, an exact mathematical model based on Fick's second diffusion law was developed to predict the release rate of polymercoated fertilizer using a numerical solution and Fourier series expansion [156]. The release time $\left(t^{\prime}\right)$ during the initial stage was defined by Eq. (11):

$$
t^{\prime}=\frac{\gamma r l}{3 p_{h} \Delta P}
$$

where $\gamma$ is total granule porosity including also voids between the nutrient core and the membrane; $p_{h}$ is water permeability of the membrane (in $\mathrm{mm}^{2} \mathrm{~Pa}^{-1}$ day $^{-1}$ ); $\Delta P$ is the vapor pressure difference between water and saturated nutrient solution (in Pa); and $r$ is radius of diffusion (in $\mathrm{mm}$ ) in the coated granule [156].

By considering that the nutrient release rate is almost zero in the initial stage, the percentage of released nutrient $\left(g_{t}\right)$ is given by Eq. (12):

$$
g_{t}=\frac{Q_{t}}{M_{0}}=0 \text { for } t \leqslant t^{\prime}
$$

where $Q_{t}$ is the quantity of diffusion (in $\mathrm{kg}$ ) up to time $t$.

The release profiles for the second and third stages are determined by the transient diffusion mechanisms which describe either the accumulation or release rate of a solute into a specific phase, promoting the variation of concentration as a function of time. A mathematical representation for these profiles can be seen in Eq. (13):

$$
C_{A}=f(t)=\frac{\partial C_{A}}{\partial t}
$$

in which $C_{A}$ is the solute concentration; and $t$ is the release time. Based on this approach, the release profiles in the second and third stages are described by Eqs. (14) and (15), respectively:

$$
\begin{aligned}
& g_{t}=\frac{3}{p_{s} r}\left(\frac{D\left(t-t^{\prime}\right)}{l} C_{s}-\frac{1}{6}\right) \quad \text { for } \quad t^{\prime}<t \leqslant Y \\
& g_{t}=1-\frac{C_{s}}{p_{s}} \exp \left(-\frac{3 D}{r l}(t-Y)\right) \text { for } t>Y
\end{aligned}
$$

where $Y$ is the time when all the solid nutrients are dissolved (in days); $\rho_{s}$ is the nutrient density (in $\mathrm{kg} \mathrm{m}^{-3}$ ); $D$ is the constant diffusion coefficient; and $C_{s}$ is the saturated concentration of nutrients (in $\mathrm{kg} \mathrm{m}^{-3}$ ).

As the nutrient release from a controlled release granule will only occur after their saturation with water [158], it is important to determine the saturation time that occurs in the initial stage of contact between water and granule containing nutrients. A mathematical model coupled with computer simulation was appropriately developed for this purpose as described elsewhere [153]. Other mathematical models for controlled nutrient release from polymer granules were described and studied. For example, a simple model based on the mass transfer process [159], a model by considering single granules [155], and other ones using molecular and ionic diffusions [157] are proposed.

3.5.1.2. Release profile from hydrogels. Most of the mathematical models developed for controlled nutrient release are focused on the release from coated polymers in the granules form, as described elsewhere $[153,155,157,159,160]$. However, the application of such models in the preparation of controlled-release fertilizers is not usual due to the difficulties for obtaining certain parameters required by the mathematical equations and simple relationships between the release rate and the apparent properties of carrier materials [161]. Nevertheless, nutrient carriers based on chemically crosslinked SH are easier to prepare and their release is more reliable than coated polymers [161]. As the nutrient release from chemically crosslinked 
polymer networks is driven by the concentration gradient between the interior and exterior of the hydrogel, it responds more precisely to the nutrient demands of the plant [161]. Besides being driven by concentration gradient, this type of release is appropriately described by other three processes: (i) penetration of water by diffusion processes through porous structures, (ii) controlled nutrient release by combination of diffusion process and/or convective flows [149,158,159], and (iii) macromolecular chain relaxation during swelling and deswelling of polymer hydrogels [114]. These processes are commonly described by either Fickian or non-Fickian mathematical diffusion models as cited previously in the section for water diffusion mechanism (Section 3.2.2). It is important to highlight that water absorption and nutrient release profiles are affected by the polymer types and crosslinking density performed during the hydrogel synthesis, and also by the ionic strength and $\mathrm{pH}$ of solutions [98,136,149,159].

Other mathematical model developed for nutrient release from hydrogels is based in the logistic growth which describes the change of nutrient concentration as a function of the release time in given volumes of water/nutrient solution. In this model, a damping coefficient related to the rate of mass transfer in the hydrogel was introduced to modify the instantaneous release rate [161]. In static release experiments, the increase in the nutrient concentration $(C(t))$ as a function of the release time $(t)$ may be considered analogous to the logistic growth of a population in the environment with limited resource [162]. Based on this assumption, a mathematical model for the nutrient release profile is described by Eq. (16):

$$
\frac{d C}{d t}=k_{R}\left(1-\frac{C}{C_{\infty}}\right)
$$

where $C_{\infty}$ is the equilibrium nutrient concentration, similar to the carrying capacity of the environment in logistic growth model and $k_{R}$ is the release rate.

By considering that the nutrient release rates from hydrogels with time is a nonlinear relation, since the diffusion velocity during the mass transfer inside polymer hydrogel matrix is slower than in water, the mathematical solution for determining the nutrient release profile is presented in Eq. (17) [161].

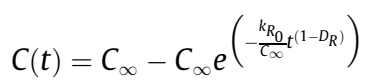

where $C(t)$ is the nutrient concentration in a given time $t, k_{R O}$ is the initial nutrient release rate from hydrogels which is related to the primary concentration and to the temperature of the experimental system, and to $D_{R}\left(0<D_{R}<1\right)$ that is the damping coefficient which is related to the characteristic mass transfer in hydrogels. By plotting $C(t) v s$. $t$, the values of $k_{R o}$ and $D_{R}$ are determined. Although there are no many specific mathematical models in order to study the nutrient release profile from hydrogels, the Fickian and non-Fickian logistic growth models are excellent alternatives to improve the synchronism between the release and the requirements of plant uptake. In addition, they could help during preparation of controlled-release nutrient hydrogels.

A diffusion-based mathematical model that considers drug release as a result of partitioning between the medium and the hydrogel, with an introduced partition activity coefficient, was developed by Reis et al. [163]. The model provides an important insight on affinity of the drug for its environment and can predict $100 \%$ of in vitro release. It shows two main limitations: (i) applicability is restricted to short releases and (ii) does not consider erosion. Following such approach, different researchers has been used this model that showed robustness for describing the whole release profile in different systems [164-166].

The mathematical development was made taking into account the Fick's second law using a simple one dimensional model. In such a model the fraction of released solute, $F_{R}$, is that given by Eq. (10). It is related to the distribution of the solute into the 3D matrix and the external fluid defined as $\alpha$ parameter (or partition activity) that evaluates the partition phenomena [163]. Once the partition exists, i.e. different solubility of solute between the 3D matrix hydrogel and the external fluid, there will transport of solute into, through or from hydrogel. After a certain interval of time, a dynamic equilibrium in such a transport will be achieved. After equilibrium has been reached, which is the stage at which the rate of release from hydrogel is equal to the rate of solute absorption into it, the $\alpha$ parameter can be calculated and should be a constant value. In equilibrium condition, the fraction of released solute acquires the maximum value, labeled as $F_{\max }$. The value of $\alpha$ can be calculated from the $F_{\max }$ value through the Eq. (18) [163]

$$
\alpha=\frac{F_{\max }}{1-F_{\max }}
$$

The value of $\alpha$ express the physical and chemical affinities of the solute for the hydrogel matrix and for the external fluid. The diffusion of solute from hydrogel into external fluid occurs even that $\alpha>0$. Also, as higher the $\alpha$ value is higher is the affinity of solute for the external fluid. Considering the solute release as a reversible process and applying pertinent mathematical arguments, [163] developed equations that described the release associated to first and second order kinetics, as follows:

A fraction of released solute, $F_{R}$, in a given release time $t$, related to the first order reversible kinetic can be calculated through the following equation [163]

$$
F_{\text {max }} \ln \left(\frac{F_{\max }}{F_{\max }-F_{R}}\right)=k_{R} t
$$


that can be rearranged to

$$
F_{R}=F_{\max }\left(1-e^{-\left(k_{R} / F_{\max }\right) t}\right)
$$

But, if the release occurs through a second order reversible kinetic, the following equation [163] can be used

$$
\frac{\alpha}{2} \ln \left(\frac{F_{R}-2 F_{R} F_{\max }+F_{\max }}{F_{\max }-F_{R}}\right)=k_{R} t
$$

that can be rearranged to

$$
F_{R}=\frac{F_{\max }\left(e^{2\left(k_{R} / \alpha\right) t}-1\right)}{1-2 F_{\max }+e^{2\left(k_{R} / \alpha\right) t}}
$$

The values of $F_{R}$, in any release time, depend of $k_{R}$ and $F_{\max }$ values and, according to Eq. (18), the last one is related to the value of $\alpha$. Once the value of $F_{\max }$ (and the concomitant $\alpha$ ), the value of $k_{R}$ can be determined by plotting the left hand of Eqs. (19) and (21), taking into account the values of $F_{R}$ as a function of time [163].

3.5.1.3. Model for water transport from hydrogel-soil-plant. To determine the capacity of the SH to act as soil conditioner, improving the amount of transported water to plant, the SH samples are submitted into an environment in which the difference in pressure between the soil and the root of vegetal is simulated. A way of doing this is to measure the water uptake at different pressures. The hydrogels are added into a vessel with Richard membrane-covered walls. The water is withdrawn from hydrogels by increasing the pressure of the vessel. The data of water content are obtained as a function of water retention $(\theta)$ (given in $\mathrm{kg}$ water per kg hydrogel) under pressure $(\psi)$ giving in hector Pascal (hPa). The experimental data are fitted to van Genuchten's equation [167], described by Eq. (23)

$$
\theta=f(\psi)=\theta_{r}+\left(\theta_{s}-\theta_{r}\right) \times\left[1+(\alpha+\psi)^{n^{\prime}}\right]^{-m}
$$

where $\theta$ (in $\mathrm{kg} \mathrm{kg}^{-1}$ ) refers the water retention curve defining the water content as a function of the pressure ( $\psi$ ) (in hPa), $\theta_{s}$ and $\theta_{r}$ are residual and saturated water contents, $m$ is a fitting parameter, and $\alpha^{\prime}$ and $n^{\prime}$ are curve shape parameters [167].

\section{Applications of $\mathrm{SH}$ based on polysaccharides in agriculture}

In spite there are a plenty of SH formulations developed in laboratory scale, only a fraction of them fulfills some important environmental-friendly requests such as nontoxicity, biodegradability and others, thus, with potential to be effectively applied in agriculture [168]. But, for economic reasons, only very few formulations effectively reached to the market as commercial products. The review from Zohuriaan-Mehr et al. published in 2010 [169] gives very good information concerning the commercial SH on agriculture (included the horticulture) and ornamental plants.

The use of SH as a soil conditioner for agriculture is a relatively old idea, dating back to 1966 [83]. However, the commercialization of these materials only occurred in the early 1980s. They reached their peak of commercial success as disposable diaper products $[140,170]$, but it has been only at the end of that decade that technical information, such as structure and property, actually came to be known. Although hundreds of patents have been deposited [83] the number of scientific papers on SH is not very significant, as compared with the number of papers on "non-superabsorbent" hydrogels. This is due to a great deal of interest in the commercialization of such materials. In the agriculture, for instance, SH can be used to preserve the water in the soil and carriers for nutrients (plant and soil). Often, the SH in granular or particle forms are mixed with soil at a $0.1 \%$ concentration [83].

Over the past few decades, several types of SH based on polysaccharides have been proposed for agriculture applications [171-173], due to their excellent hydrophilic properties (high swelling capacity and high swelling rate), excellent biocompatibility and biodegradability. Due to the low cost, abundance, and eco-friendly properties, the polysaccharides are pointed as substitutes of petroleum derivatives in the preparation of $\mathrm{SH}[174,175]$. The high water absorption of these materials is attributed to the interconnected superpore structures with diameters of several hundred microns, creating open channels that allow for capillary action [176]. Additionally, when are added in the soil, SH reduces the irrigation water consumption and improve the soil's physical properties [173]. Accordingly, the SH act as water reservoir, releasing the water in a controlled way to soil or directly to vegetal specimens. Another advantages related to use of SH in agriculture is to lower the death rate of plants and increase output of crops in arid belts [177].

\subsection{Application as soil conditioners}

An attractive approach that has been more recently investigated involves the controlled release of nutrients from the fertilizer-loaded hydrogel into crops. A large portion of the fertilizer applied to soil is lost by leaching, principally in highly porous soils, chemical process, excess of rains and so on. A number of different polysaccharides, such as chitosan [178], pectin [133], carboxymethyl cellulose [83] and so forth, has been used to prepare hydrogels as a fertilizer release system to nurture the soil. To load the hydrogels with nutrients, two approaches are used: (i) post-loading (after the hydrogel processing); (ii) in situ loading (during the hydrogel processing). The post-synthesis approach is performed by swelling the hydrogel together 


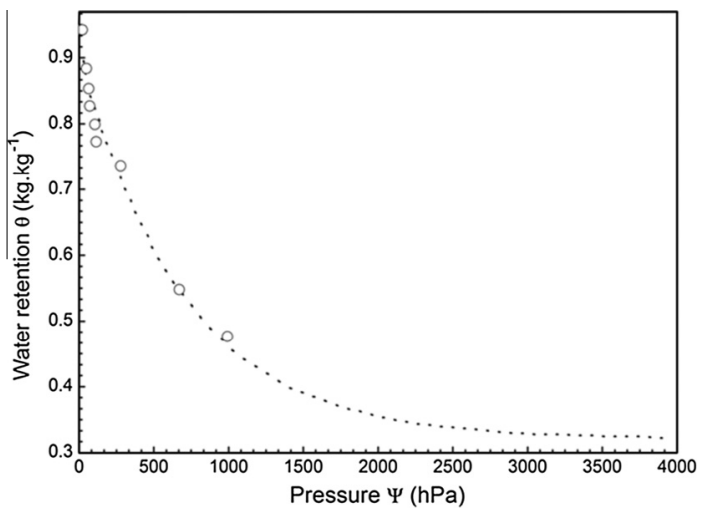

Fig. 2. Curve of water retention $\theta$ defining the water content as a function of the pressure $\Psi$ (hPa, hectoPascal), see Eq. (23) on hydrogel (15-50-35) being this label representing the amount (in wt.\%) of chemically modified Pec (M-Pec), acrylamide (AAm) and sodium acrylate (NaAAc) used in hydrogel synthesis. Reprinted with permission from Ref. [133].

with active substance, which diffuses into the polymer network by absorption (quantified through Eq. (5)). The efficiency of such a strategy is related to physical-chemical affinity of the fertilizer for polymer chains forming hydrogel. The in situ approach is preferred over post-loading one because of the greater loading efficiency [131]. The loaded material is dried prior being added to crop. The release is activated by swelling during the soil irrigations, or even during the rains. The water within the hydrogel dissolves the nutrient, which can diffuse through polymer network. The movement of solutes toward the outside of the hydrogel can be related with swelling rate $[179,180]$. Not all load of the substance in the hydrogel is released. As a result, a portion of loaded solute is preserved when the hydrogel dries in the intervals of irrigations or rains. The release is again activated in the further watering processes, thus providing a prolonged release process that can prevent the leaching. It is also possible to load two or more active substances onto hydrogel so that each one of them may have specific release kinetic. A way of doing this is to determine the release rate constants for each loaded substance.

Several authors have shown their contributions on application of hydrogel and SH as soil conditioners. For instance, Agaba et al. [181] indicated that the moisture retention of specific soil due to SH is essential to plantation forest establishment, and once the water influences the soil properties such as aeration, temperature and nutrient transport, water uptake and transformation, which affects the plant growth. Demitri et al. [182] investigated the applicability of the cellulose-based SH in three different formulations, crosslinked by carbodiimide, as a carrier vehicle for sustained and controlled release of water and nutrients in arid and desert areas. According to the authors, the main advantage is that the hydrogels may control the release of stored water as the soil dries, maintaining the soil humidity over relatively long time. Also, the presence of hydrogel increases the soil porosity that provides a better oxygenation to the plant roots. Parvathy and Jyothi [183] studied the effect of a SH based on saponified cassava starch-g-poly(acrylamide) on the physical-chemical and biological properties of soil. They also investigated the effect of the same hydrogel on the growth parameters of chili (Capsicum annuum L.) in different irrigation intervals. The results showed that amount of moisture retained in the soil were dependent of the concentration of superabsorbent matrices, what provides a better control of release of adsorbed water. They also indicated that these SH are potential candidates to be applied as an alternative to combat of global climate change because they can improve the soil properties, mainly in conditions of reduced moisture availability. Other authors investigated the applicability of the polymers, common hydrogels and SH as strategies to improve the soil properties [184-201].

Hydrogels based on chemically modified pectin were used to release phosphate, potassium, and urea. Swellings were measured in distilled water and saline solutions at different pressures [133]. Fig. 2 shows the curve obtained after treatment of data according to Eq. (17), water retention $(\theta)$ as a function of the pressure $(\psi)$ for $0.05 \mathrm{~g} \mathrm{~mL}^{-1}$ hydrogel (15-50-35) being this label representing the amount (in wt.\%) of chemically modified Pec (M-Pec), acrylamide (AAm) and sodium acrylate $(\mathrm{NaAAc})$ used in hydrogel synthesis. The saturated moisture $\left(\theta_{s}\right)$ and residual moisture $\left(\theta_{r}\right)$ at $4,000 \mathrm{hPa}$ were 0.567 and $0.333 \mathrm{~kg} \mathrm{~kg}^{-1}$, respectively (see Eq. (17)). According to the authors, the capability of hydrogel to conserve water residues in a pressure range in which a variety of horticultural plants can absorb water makes the as-obtained hydrogel an attractive material for soil conditioning [133].

\subsection{Application as nutrient carriers}

Controlled solute release on soils may be carried out from many types of chemically crosslinked hydrogels. Some examples include: (i) crosslinked poly(vinyl alcohol) hydrogel for release of herbicide paraquat, resulting in higher percentages of compound released through use of lower concentrations for crosslinking during hydrogel synthesis [202]; (ii) polyacrylamide hydrogels for controlled 2,4-dichlorophenoxyacetic acid release [203]; (iii) alginate-based hydrogels in controlled NSO release [204]; (vi) crosslinked amide hydrogel as carrier for controlled urea release [205]; (v) controlled root targeted release of fertilizer using an ionically crosslinked carboxymethyl-cellulose hydrogel matrix [142]; (vi) sodium 
carboxymethylcellulose/hydroxyethylcellulose hydrogel applied in slow-release of nitrogen fertilizer [135]; (vii) wheat straw-g-poly(acrylic acid) superabsorbent composites for controlled urea release [206]; (viii) a series of hydrogels composed of polyacrylamide, methylcellulose, and calcic montmorillonite for the controlled fertilizer release where the components presented a synergistic effect, giving very high fertilizer loading in their structure [154]; (ix) crosslinked tragacanth gum/ acrylic acid hydrogel for utilization in controlled fertilizer release and enhancement of water-holding capacity of soil [146]; and lastly but equally important, (x) carboxymethyl chitosan-g-poly(acrylic acid)/attapulgite superabsorbent composite as carriers for agricultural nutrients [148].

Raafat et al. [138] studied a series of SH based on carboxymethylcellulose (CMC) and polyvinylpyrrolidone (PVP) crosslinked with gamma irradiation with potential application in agriculture as soil conditioner and/or nutrient carriers. From morphological studies, the authors observed that these hydrogels have highly interconnected porous network structure, which facilitates the water diffusion process through the 3D matrix. Besides, this porosity decreases when the PVP content in the feed solution increases. The hydrophilic properties indicated that the increase of CMC concentration up to 60 wt.\% provoked pronounced increase in the equilibrium swelling. This trend is related to the high hydrophilic character of CMC molecules. Beyond this concentration, decrease in hydrophilic character was observed. According to authors, this behavior was attributed to damaged network structure, which was not able to achieve high water sorption. Results of nutrient release confirmed that these SH are potential eco-friendly matrices for application as delivery vehicle for the controlled release of agrochemical nutrients.

Rashidzadeh and Olad [207] obtained a superabsorbent nanocomposite prepared via in-situ free radical polymerization based upon a sodium alginate, acrylic acid, acrylamide, and montmorillonite clay using $N, N^{\prime}$-methylene bisacrylamide and ammonium persulfate as crosslinker agent and initiator, respectively. The authors investigated the influence of some parameters on spectroscopic, structural, morphological and water absorbency of these nanocomposites, as well as on NPK slow release behavior. The results showed that the water absorbency was dependent of crosslinker-type, amount of clay, and to the $\mathrm{pH}$ and concentration of salt on solution. They concluded that these matrices have excellent slow-release property and good water retention capacity, indicating potential application in agricultural because reduced the loss of fertilizer and improved the available water. In a review paper, Campos et al. [208] presented some polysaccharides-based controlled-release formulations including hydrogel matrices. According to authors, the main advantages of polysaccharide over synthetic polymers are their eco-friendly source, low-cost, easy availability, and biodegradability. Additionally, in the hydrogel case, their presence in soil improved the soil water-holding capacity.

The release kinetic can be changed by adding inorganic particles into hydrogel (so-called hydrogel composites). The particles, when sufficiently dispersed, cause tortuosity effect that disturbs the release of solutes. Such an effect provides longer (tortuous) pathways that difficult the diffusion of the solute toward the outside hydrogels. The particles play a role as a retardant factor for drug release [85]. As a result, the release is extended for longer times. In this direction, Bortolin et al. [154] prepared SH hydrogels composed of PAAm, methylcellulose (MC), and calcic montmorillonite (MMt) with appropriate properties, after hydrolysis of AAm repeat units, for the controlled release of fertilizers. Material without MMt was used as control to check the effect of such filler (at pH 4, 7 and 9) in urea releasing, as shown in Fig. 3. According to the authors, the presence of mineral clay on hydrogels without the hydrolysis treatment, delayed the nutrient (e.g. urea) desorption in quite a significant way. However, an important factor was that, for the hydrolyzed hydrogels, desorption time and the amount of nutrient desorbed increased significantly. So the tortuosity provoked by the presence of MMt is responsible for such effect.

In that wok, in addition, the profiles of urea release were modeled using Eqs. (6), (19) and (20). The authors concluded that the model developed by Reis et al. [163] was robustness for predicting the solute release in neat and composite hydrogels for both kinetic orders (using first and second order release kinetics) showing good regression $R^{2}$ values. Also, the $\alpha$ values permitted to evaluate the solute affinity by the nanocomposite hydrogel according to the $\mathrm{pH}$ medium. The authors observed, however, for the hydrolyzed hydrogels (neat and nanocomposite ones), that the model was only adequately fitted

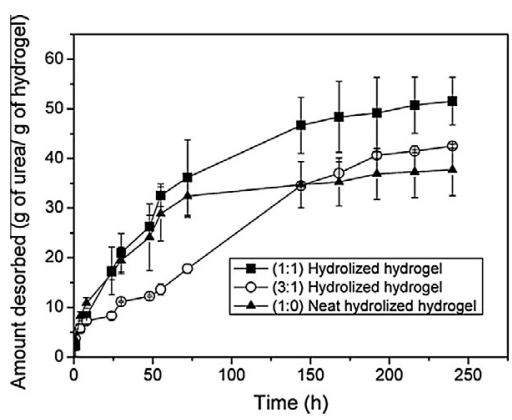

(a)

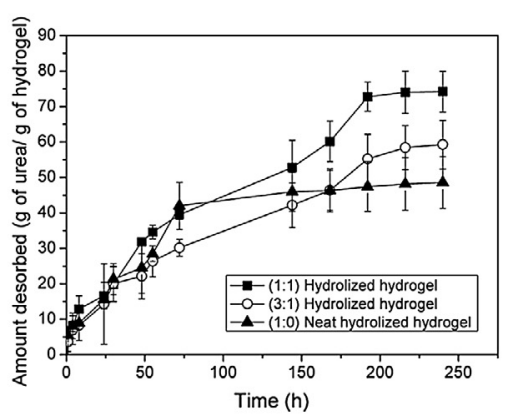

(b)

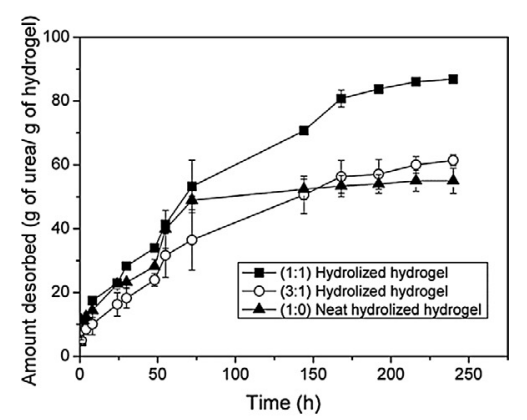

(c)

Fig. 3. Kinetic curves of the controlled desorption of urea in different pH values for the hydrolyzed hydrogels: (a) 4.0; (b) 7.0; and (c) 9.0. Used labels ( $x: y$ ) indicate the relative amount of PAAm + methyl cellulose $(=x)$ and MMt $(=y)$ used in the hydrogel preparation. Reprinted with permission from Ref. [154]. 
for first order release kinetic, which is an indicative of the easier water diffusion from nanocomposite structures to the solution.

Other controlled release nutrients systems using $\mathrm{SH}$ as carrier vehicles applied in agriculture were reported in literature $[109,161,206,209-214]$.

\section{Future trends and perspectives}

Polysaccharides have been used as a substitute for (or combining to) synthetic moieties for producing hydrogels (ordinary or superabsorbent) in very important technological applications, as environmental in waste-water treatment (e.g. as metal/ dye absorbers [215], hygienic (as feminine napkins [216], disposable diapers [217], etc.) and in agriculture (as soil conditioners and nutrient carriers) are good examples [218]. This is due mainly to the relatively low-cost, abundance, renewability, and biodegradability, among others advantages for using polysaccharides. Also, important technologies have been developed mostly in the last two decades for chemically modifying polysaccharides enabling to the preparation of hydrogel-based polysaccharides. Some examples were given in this review, but a very large window in this issue remains opened [219]. As a trend for this field, some highlights can be given, among others:

(i) Preparation of hydrogels of low cost, that can show, at same time, superabsoption characteristics and good mechanical properties. This remains as a challenge to be confronted, despite some works showing that the incorporation of nanofillers either from polysaccharides, such as nanowhiskers, nanfibrils, [15] or from inorganic sources, such as kaolin [220], montmorillonite [221], and attapulgite [222], may improve the swelling ratio, the swelling rate and mechanical properties [217].

(ii) Developing eco-friendly methods for chemically modifying polysaccharides allowing chemical crosslinking or providing permanent electrical charges in polymer backbone for physical hydrogel formation (through polyelectrolyte complexation). The review from Prado and Matulewicz [223] is a very important updated reference in this issue.

(iii) Producing SH in nanoscale (nanogels) with very high water (or aqueous solution) uptake capability (e.g. thousandsfold). Their properties can be improved by incorporating CNCs into formulations, prepared mainly by inverse mini emulsion methods. In addition, technologies associated to nanoparticles may reduce the sensitivity of SH to saline conditions.

(iv) Lowering the final cost production remains as a challenge [224] for applications of SH in agriculture, in a large scale. Even the ecological requirements are filled (such as no toxicity to soil or plant), biodegradability and so on, the final price will be an mandatory parameter for spreading more and more the use of SH as soil conditioner and/or nutrient carriers.

Of course, more comprehensive studies will expand the understanding of structure-properties-applications relationship in SH. This will, certainly, increase the importance of the class of soft materials.

\section{Conclusions}

This review attempted to update and discuss some important aspects of synthesis, characterization and application of SH, mainly those based on polysaccharides, as soil conditioners and as carriers for nutrient release. Some methods for chemically modifying polysaccharides were given and some directions for hydrogels preparation as well. Mechanisms associated to water transport into the 3D matrix were discussed on the light of some mathematical models. The release of nutrients from granules coated by hydrophilic polymer or from SH, targeting applications in agriculture, were also discussed based on often used mathematical models and on alternative model based on diffusion-partition. Despite patents and papers announcing novel SHs or SHs with new structures and properties appear almost every day in literature, future trends and perspectives given at the final of review demonstrate that a large window of opportunities remains opened in this field. It was reinforced that $\mathrm{SH}$ remain as very hot issue in materials science due to both intensive academic researches and technological applications. Of course, more comprehensive studies will expand the understanding of structure-properties-applications relationship in $\mathrm{SH}$, which will, certainly, increase even more the importance of the class of soft materials.

\section{Acknowledgments}

Authors thank the financial support from Conselho Nacional de Desenvolvimento Científico e Tecnológico (CNPq, Brazil), Grant \#400702/2012-6, \#308337/2013-1 and \#167432/2013-3; and from Coordenação de Aperfeiçoamento de Pessoal de Nível Superior (CAPES, Brazil) and also from Fundação Araucária (Paraná, Brazil).

\section{References}

[1] Y. Zhang, H.F. Chan, K.W. Leong, Advanced materials and processing for drug delivery: the past and the future, Adv. Drug Deliv. Rev. 65 (1) (2013) $104-120$.

[2] B.D. Ulery, L.S. Nair, C.T. Laurencin, Biomedical applications of biodegradable polymers, J. Polym. Sci. Part B - Polym. Phys. 49 (12) (2011) $832-864$. 
[3] L. Rizzello, R. Cingolani, P.P. Pompa, Nanotechnology tools for antibacterial materials, Nanomedicine 8 (5) (2013) $807-821$.

[4] D. Bastani, N. Esmaeili, M. Asadollahi, Polymeric mixed matrix membranes containing zeolites as a filler for gas separation applications: a review, J. Indust. Eng. Chem. 19 (2) (2013) 375-393.

[5] S. Kango, S. Kalia, A. Celli, J. Njuguna, Y. Habibi, R. Kumar, Surface modification of inorganic nanoparticles for development of organic-inorganic nanocomposites - a review, Progr. Polym. Sci. 38 (8) (2013) 1232-1261.

[6] L. Sartore, G. Vox, E. Schettini, Preparation and performance of novel biodegradable polymeric materials based on hydrolyzed proteins for agricultural application, J. Polym. Environ. 21 (3) (2013) 718-725.

[7] O. Wichterle, D. Lim, Hydrophilic gels for biological use, Nature 185 (4706) (1960) 117-118.

[8] C. Chang, B. Duan, J. Cai, L. Zhang, Superabsorbent hydrogels based on cellulose for smart swelling and controllable delivery, Eur. Polym. J. 46 (1) (2010) 92-100.

[9] A. Pourjavadi, A.M. Harzandi, H. Hosseinzadeh, Modified carrageenan 3. Synthesis of a novel polysaccharide-based superabsorbent hydrogel via graft copolymerization of acrylic acid onto kappa-carrageenan in air, Eur. Polym. J. 40 (7) (2004) 1363-1370.

[10] W.E. Hennink, C.F. van Nostrum, Novel crosslinking methods to design hydrogels, Adv. Drug Deliv. Rev. 64 (2012) $223-236$.

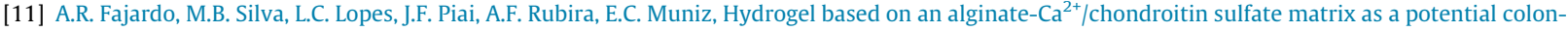
specific drug delivery system, RSC Adv. 2 (29) (2012) 11095-11103.

[12] F. Bordi, G. Paradossi, C. Rinaldi, B. Ruzicka, Chemical and physical hydrogels: two casesystems studied by quasi elastic light scattering, Physica A Statistical Mech. Appl. 304 (1-2) (2002) 119-128.

[13] E.M. Ahmed, Hydrogel: preparation, characterization, and applications, J. Adv. Res. (2013) 17.

[14] W.A. Laftah, S. Hashim, A.N. Ibrahim, Polymer hydrogels: a review, Polym. - Plast. Technol. Eng. 50 (14) (2011) $1475-1486$.

[15] F.H.A. Rodrigues, C. Spagnol, A.G.B. Pereira, A.F. Martins, A.R. Fajardo, A.F. Rubira, et al, Superabsorbent hydrogel composites with a focus on hydrogels containing nanofibers or nanowhiskers of cellulose and chitin, J. Appl. Polym. Sci. 131 (2) (2014).

[16] H. Omidian, J.G. Rocca, K. Park, Advances in superporous hydrogels, J. Control. Release 102 (1) (2005) 3-12.

[17] K.S. Kazanskii, S.A. Dubrovskii, Chemistry and physics of agricultural hydrogels, Adv. Polym. Sci. 104 (1992) 97-133.

[18] T. Mekonnen, P. Mussone, H. Khalil, D. Bressler, Progress in bio-based plastics and plasticizing modifications, J. Mater. Chem. A 1 (43) (2013) 13379_ 13398.

[19] M. Rinaudo, Chitin and chitosan: properties and applications, Progr. Polym. Sci. 31 (7) (2006) 603-632.

[20] T. Heinze, T. Liebert, B. Heublein, S. Hornig, Functional polymers based on dextran, Adv. Polym. Sci. 205 (2006) $199-291$.

[21] Y. Zhao, J. Kang, T. Tan, Salt-, pH- and temperature-responsive semi-interpenetrating polymer network hydrogel based on poly(aspartic acid) and poly(acrylic acid), Polymer 47 (22) (2006) 7702-7710.

[22] S. Yan, J. Yin, Y. Yu, K. Luo, X. Chen, Thermo- and pH-sensitive poly(vinylmethyl ether)/carboxymethylchitosan hydrogels crosslinked using electron beam irradiation or using glutaraldehyde as a crosslinker, Polym. Int. 58 (11) (2009) 1246-1251.

[23] A.C. Lima, W. Song, B. Blanco-Fernandez, C. Alvarez-Lorenzo, J.F. Mano, Synthesis of temperature-responsive Dextran-MA/PNIPAAm particles for controlled drug delivery using superhydrophobic surfaces, Pharma. Res. 28 (6) (2011) 1294-1305.

[24] T. Gotoh, Y. Nakatani, S. Sakohara, Novel synthesis of thermosensitive porous hydrogels, J. Appl. Polym. Sci. 69 (5) (1998) 895-906.

[25] L. Klouda, A.G. Mikos, Thermoresponsive hydrogels in biomedical applications, Eur. J. Pharma. Biopharma. 68 (1) (2008) $34-45$.

[26] K. Kabiri, M.J. Zohuriaan-Mehr, Superabsorbent hydrogel composites, Polym. Adv. Technol. 14 (6) (2003) $438-444$.

[27] J.H. Wu, J.M. Lin, M. Zhou, C.R. Wei, Synthesis and properties of starch-graft-polyacrylamide/clay superabsorbent composite, Macromol. Rapid Commun. 21 (15) (2000) 1032-1034.

[28] M.R. Guilherme, A.V. Reis, S.H. Takahashi, A.F. Rubira, J.P.A. Feitosa, E.C. Muniz, Synthesis of a novel superabsorbent hydrogel by copolymerization of acrylamide and cashew gum modified with glycidyl methacrylate, Carbohydr. Polym. 61 (4) (2005) 464-471.

[29] A.S. Hoffman, Hydrogels for biomedical applications, Adv. Drug Deliv. Rev. 54 (1) (2002) 3-12.

[30] P. Gupta, K. Vermani, S. Garg, Hydrogels: from controlled release to pH-responsive drug delivery, Drug Discov. Today 7 (10) (2002) $569-579$.

[31] S.W. Kim, Y.H. Bae, T. Okano, Hydrogels - swelling, drug loading, and release, Pharma. Res.. 9 (3) (1992) $283-290$.

[32] N.A. Peppas, P. Bures, W. Leobandung, H. Ichikawa, Hydrogels in pharmaceutical formulations, Eur. J. Pharma. Biopharma. 50 (1) (2000) 27-46.

[33] O. Okay, Macroporous copolymer networks, Progr. Polym. Sci. 25 (6) (2000) 711-779.

[34] M.R. Guilherme, A.V. Reis, A.T. Paulino, A.R. Fajardo, E.C. Muniz, E.B. Tambourgi, Superabsorbent hydrogrel based on modified polysaccharide for removal of $\mathrm{Pb}^{2+}$ and $\mathrm{Cu}^{2+}$ from water with excellent performance, J. Appl. Polym. Sci. 105 (5) (2007) $2903-2909$.

[35] H. Kitano, K. Sudo, K. Ichikawa, M. Ide, K. Ishihara, Raman spectroscopic study on the structure of water in aqueous polyelectrolyte solutions, J. Phys. Chem. B 104 (47) (2000) 11425-11429.

[36] J.d.S. Candido, A.G.B. Pereira, A.R. Fajardo, N.M.P.S. Ricardo, J.P.A. Feitosa, E.C. Muniz, et al, Poly(acrylamide-co-acrylate)/rice husk ash hydrogel composites. II. Temperature effect on rice husk ash obtention, Compos. Part B - Eng.. 51 (2013) 246-253.

[37] A. Domjan, G. Erdodi, M. Wilhelm, M. Neidhofer, K. Landfester, B. Ivan, et al, Structural studies of nanophase-separated poly(2-hydroxyethyl methacrylate)-l-polyisobutylene amphiphilic conetworks by solid-state NMR and small-angle X-ray scattering, Macromolecules 36 (24) (2003) 9107-9114.

[38] C.G.T. Neto, J.A. Giacometti, A.E. Job, F.C. Ferreira, J.L.C. Fonseca, M.R. Pereira, Thermal analysis of chitosan based networks, Carbohydr. Polym. 62 (2) (2005) 97-103.

[39] J.S. Park, J.W. Park, E. Ruckenstein, Thermal and dynamic mechanical analysis of PVA/MC blend hydrogels, Polymer 42 (9) (2001) 4271-4280.

[40] L. Yin, L. Fei, F. Cui, C. Tang, C. Yin, Superporous hydrogels containing poly(acrylic acid-co-acrylamide)/O-carboxymethyl chitosan interpenetrating polymer networks, Biomaterials 28 (6) (2007) 1258-1266.

[41] N. Sahiner, H. Ozay, O. Ozay, N. Aktas, New catalytic route: hydrogels as templates and reactors for in situ Ni nanoparticle synthesis and usage in the reduction of 2-and 4-nitrophenols, Appl. Catal. A - Gen. 385 (1-2) (2010) 201-207.

[42] N.V. Gupta, H.G. Shivakumar, Investigation of swelling behavior and mechanical properties of a pH-sensitive superporous hydrogel composite, Iran. J. Pharma. Res. 11 (2) (2012) 481-493.

[43] M. Ramezani, M. Jafari, A. Tavili, S.A. Javadi, Q.Z. Amiri, The effect of calcium and sodium chloride levels on the dehydration power of hydrophilic polymer, J. Food Agric. Environ. 11 (2) (2013) 896-898.

[44] E.V. Ramos Campos, J.L. de Oliveira, L.F. Fraceto, B. Singh, Polysaccharides as safer release systems for agrochemicals, Agronomy Sustain. Develop. 35 (1) (2015) 47-66.

[45] Y. Cheng, L. Lu, W. Zhang, J. Shi, Y. Cao, Reinforced low density alginate-based aerogels: preparation, hydrophobic modification and characterization, Carbohydr. Polymers. 88 (3) (2012) 1093-1099.

[46] C. Spagnol, F.H.A. Rodrigues, A.G.B. Pereira, A.R. Fajardo, A.F. Rubira, E.C. Muniz, Superabsorbent hydrogel composite made of cellulose nanofibrils and chitosan-graft-poly(acrylic acid), Carbohydr. Polym. 87 (3) (2012) 2038-2045.

[47] P.C. Parvathy, A.N. Jyothi, Water sorption kinetics of superabsorbent hydrogels of saponified cassava starch-graft-poly(acrylamide), Starch-Starke 64 (10) (2012) 803-812.

[48] M. Sadeghi, H. Hosseinzadeh, Synthesis and superswelling behavior of carboxymethylcellulose-poly(sodium acrylate-co-acrylamide) hydrogel, J. Appl. Polym. Sci. 108 (2) (2008) 1142-1151.

[49] A. Pourjavadi, M. Sarnadi, H. Ghasernzadeh, Fast-swelling superabsorbent hydrogels from poly(2-hydroxy ethyl acrylate-co-sodium acrylate) grafted on starch, Starch-Starke 60 (2) (2008) 79-86.

[50] H.A. Abd El-Rehim, E.S.A. Hegazy, H.L. Abd El-Mohdy, Radiation synthesis of hydrogels to enhance sandy soils water retention and increase plant performance, J. Appl. Polym. Sci. 93 (3) (2004) 1360-1371. 
[51] V.R. Sinha, R. Kumria, Polysaccharides in colon-specific drug delivery, Int. J. Pharma. 224 (1-2) (2001) 19-38.

[52] P. Baldrian, V. Valaskova, Degradation of cellulose by basidiomycetous fungi, FEMS Microbiol. Rev. 32 (3) (2008) 501-521.

[53] A. Villay, F.L. de Filippis, L. Picton, D. Le Cerf, C. Vial, P. Michaud, Comparison of polysaccharide degradations by dynamic high-pressure homogenization, Food Hydrocolloids 27 (2) (2012) 278-286.

[54] A.R. Fajardo, A.F. Rubira, E.C. Muniz, Dual-network hydrogels based on chemically and physically crosslinked chitosan/chondroitin sulfate, React. Funct. Polym. 73 (12) (2013) 1662-1671.

[55] A. Sannino, L. Nicolais, Concurrent effect of microporosity and chemical structure on the equilibrium sorption properties of cellulose-based hydrogels, Polymer 46 (13) (2005) 4676-4685.

[56] F. Lionetto, A. Sannino, A. Maffezzoli, Ultrasonic monitoring of the network formation in superabsorbent cellulose based hydrogels, Polymer 46 (6) (2005) 1796-1803.

[57] G. Marci, G. Mele, L. Palmisano, P. Pulito, A. Sannino, Environmentally sustainable production of cellulose-based superabsorbent hydrogels, Green Chem. 8 (5) (2006) 439-444.

[58] A. Sannino, A. Maffezzoli, L. Nicolais, Introduction of molecular spacers between the crosslinks of a cellulose-based superabsorbent hydrogel: effects on the equilibrium sorption properties, J. Appl. Polym. Sci. 90 (1) (2003) 168-174.

[59] W. Wang, L. Zong, A. Wang, A nanoporous hydrogel based on vinyl-functionalized alginate for efficient absorption and removal of Pb ${ }^{2+}$ ions, Int. J. Biol. Macromol. 62 (2013) 225-231.

[60] M.R. Guilherme, T.A. Moia, A.V. Reis, A.T. Paulino, A.F. Rubira, L.H.C. Mattoso, et al, Synthesis and water absorption transport mechanism of a pHsensitive polymer network structured on vinyl-functionalized pectin, Biomacromolecules 10 (1) (2009) 190-196.

[61] A.V. Reis, M.R. Guilherme, O.A. Cavalcanti, A.F. Rubira, E.C. Muniz, Synthesis and characterization of pH-responsive hydrogels based on chemically modified Arabic gum polysaccharide, Polymer 47 (6) (2006) 2023-2029.

[62] M.R. Guilherme, R.S. Oliveira, M.R. Mauricio, T.S.P. Cellet, G.M. Pereira, M.H. Kunita, et al, Albumin release from a brain-resembling superabsorbent magnetic hydrogel based on starch, Soft Matter 8 (24) (2012) 6629-6637.

[63] W.N.E. Vandijkwolthuis, O. Franssen, H. Talsma, M.J. Vansteenbergen, J.J.K. Vandenbosch, W.E. Hennink, Synthesis, characterization, and polymerization of glycidyl methacrylate derivatized dextran, Macromolecules 28 (18) (1995) 6317-6322.

[64] W.N.E. vanDijkWolthuis, J.J. KettenesvandenBosch, A. vanderKerkvanHoof, W.E. Hennink, Reaction of dextran with glycidyl methacrylate: an unexpected transesterification, Macromolecules 30 (11) (1997) 3411-3413.

[65] A.V. Reis, A.R. Fajardo, I.T.A. Schuquel, M.R. Guilherme, G.J. Vidotti, A.F. Rubira, et al, Reaction of glycidyl methacrylate at the hydroxyl and carboxylic groups of poly(vinyl alcohol) and poly(acrylic acid): is this reaction mechanism still unclear?, J Org. Chem. 74 (10) (2009) $3750-3757$.

[66] L. Ferreira, M.M. Vidal, C. Geraldes, M.H. Gil, Preparation and characterisation of gels based on sucrose modified with glycidyl methacrylate, Carbohydr. Polym. 41 (1) (2000) 15-24.

[67] Q. Li, D.A. Wang, J.H. Elisseeff, Heterogeneous-phase reaction of glycidyl methacrylate and chondroitin sulfate: mechanism of ring-openingtransesterification competition, Macromolecules 36 (7) (2003) 2556-2562.

[68] H.I.M. Ismail, Z. Ahmad, Starch-based hydrogels: present status and applications, Int. J. Polym. Mater. Polym. Biomater. 62 (7) (2013) 9.

[69] M.L.Q. Diao, H. Xiao, N. Duan, J. Xu, Synthesis and adsorption properties of superabsorbent hydrogel and peanut hull composite, J. Environ. Chem. Eng. 2 (3) (2014) 1558-1567.

[70] Y. Bao, J. Ma, N. Li, Synthesis and swelling behaviors of sodium carboxymethyl cellulose-g-poly(AA-co-AM-co-AMPS)/MMT superabsorbent hydrogel, Carbohydr. Polym. 84 (1) (2011) 76-82.

[71] W. Wang, A. Wang, Synthesis and swelling properties of pH-sensitive semi-IPN superabsorbent hydrogels based on sodium alginate-g-poly(sodium acrylate) and polyvinylpyrrolidone, Carbohydr. Polym. 80 (4) (2010) 1028-1036.

[72] E. Feng, G. Ma, Y. Wu, H. Wang, Z. Lei, Preparation and properties of organic-inorganic composite superabsorbent based on xanthan gum and loess, Carbohydr. Polym. 111 (2014) 463-468.

[73] Y. Chen, Y.-f. Liu, H.-l. Tang, H.-m. Tan, Study of carboxymethyl chitosan based polyampholyte superabsorbent polymer I Optimization of synthesis conditions and $\mathrm{pH}$ sensitive property study of carboxymethyl chitosan-g-poly(acrylic acid-co-dimethyldiallylammonium chloride) superabsorbent polymer, Carbohydr. Polym. 81 (2) (2010) 365-371.

[74] W.-B. Wang, D.-J. Huang, Y.-R. Kang, A.-Q. Wang, One-step in situ fabrication of a granular semi-IPN hydrogel based on chitosan and gelatin for fast and efficient adsorption of $\mathrm{Cu}^{2+}$ ion, Colloids Surf. B - Biointerfaces 106 (2013) 51-59.

[75] J. Zhang, Q. Wang, A. Wang, Synthesis and characterization of chitosan-g-poly(acrylic acid)/attapulgite superabsorbent composites, Carbohydr. Polym. 68 (2) (2007) 367-374.

[76] J. Liu, W. Wang, A. Wang, Synthesis, characterization, and swelling behaviors of chitosan-g-poly(acrylic acid)/poly(vinyl alcohol) semi-IPN superabsorbent hydrogels, Polym. Adv. Technol. 22 (5) (2011) 627-634.

[77] G.R.P.A. Mahdavinia, H. Hosseinzadeh, M.J. Zohuriaan, Modified chitosan 4. Superabsorbent hydrogels from poly(acrylic acid-co-acrylamide) grafted chitosan with salt- and pH-responsiveness properties, Eur. Polym. J. 40 (7) (2004) 1399-1407.

[78] A.T. Paulino, M.R. Guilherme, E.A.M.S. de Almeida, A.G.B. Pereira, E.C. Muniz, E.B. Tambourgi, One-pot synthesis of a chitosan-based hydrogel as a potential device for magnetic biomaterial, J. Magn. Magn. Mater. 321 (17) (2009) 2636-2642.

[79] J. Liu, Q. Wang, A. Wang, Synthesis and characterization of chitosan-g-poly(acrylic acid)/sodium humate superabsorbent, Carbohydr. Polym. 70 (2) (2007) 166-173.

[80] A. Pourjavadi, V. Aghajani, H. Ghasemzadeh, Synthesis, characterization and swelling behavior of chitosan-sucrose as a novel full-polysaccharide superabsorbent hydrogel, J. Appl. Polym. Sci. 109 (4) (2008) 2648-2655.

[81] A.F. Martins, J.F. Piai, I.T.A. Schuquel, A.F. Rubira, E.C. Muniz, Polyelectrolyte complexes of chitosan/heparin and N,N,N-trimethyl chitosan/heparin obtained at different pH: I. Preparation, characterization, and controlled release of heparin, Colloid Polym. Sci. 289 (10) (2011) 1133-1144.

[82] R.R. Mallepally, I. Bernard, M.A. Marin, K.R. Ward, M.A. McHugh, Superabsorbent alginate aerogels, J. Supercritical Fluids 79 (2013) $202-208$.

[83] F.L. Buchholz, A.T. Graham, Modern Superabsorbent Polymer Technology, Wiley-VCH, New York, United States, 1998.

[84] M.R. Guilherme, A.V. Reis, B.R.V. Alves, M.H. Kunita, A.F. Rubira, E.B. Tambourgi, Smart hollow microspheres of chondroitin sulfate conjugates and magnetite nanoparticles for magnetic vector, J. Colloid Interf. Sci. 352 (1) (2010) 107-113.

[85] M.R.C.P. Mauricio, S.H. Haraguchi, M.R. Guilherme, E.C. Muniz, A.F. Rubira, Synthesis of a microhydrogel composite from cellulose nanowhiskers and starch for drug delivery, Carbohydr. Polym. 115 (22) (2015) 715-722.

[86] F. Quignard, R. Valentin, F. Di Renzo, Aerogel materials from marine polysaccharides, New J. Chem. 32 (8) (2008) 1300-1310.

[87] M.R. Guilherme, M.R. Mauricio, E.T. Tenorio-Neto, M.H. Kunita, L. Cardozo-Filho, T.S.P. Cellet, et al, Polycaprolactone nanoparticles containing encapsulated progesterone prepared using a scCO(2) emulsion drying technique, Mater. Lett. 124 (2014) 197-200.

[88] Q. Wei, D. Chionna, E. Galoppini, M. Pracella, Functionalization of LDPE by melt grafting with glycidyl methacrylate and reactive blending with polyamide-6, Macromol. Chem. Phys. 204 (8) (2003) 1123-1133.

[89] P. Laurienzo, M. Malinconico, G. Mattia, G. Romano, Synthesis and characterization of functionalized crosslinkable poly(epsilon-caprolactone), Macromol. Chem. Phys. 207 (20) (2006) 1861-1869.

[90] A.V. Reis, M.R. Guilherme, E.A.M.S. de Almeida, M.H. Kunita, E.C. Muniz, A.F. Rubira, et al, Copolymer hydrogel microspheres consisting of modified sulfate chondroitin-co-poly(N-isopropylacrylamide), J. Appl. Polym. Sci. 121 (5) (2011) 2726-2733.

[91] M.R. Guilherme, M.R. de Moura, E. Radovanovic, G. Geuskens, A.F. Rubira, E.C. Muniz, Novel thermo-responsive membranes composed of interpenetrated polymer networks of alginate-Ca ${ }^{2+}$ and poly(N-isopropylacrylamide), Polymer 46 (8) (2005) 2668-2674.

[92] R. Aso, H. Kurata, T. Namikoshi, T. Hashimoto, S.-W. Kuo, F.-C. Chang, et al, Quantitative imaging of T-g in block copolymers by low-angle annular dark-field scanning transmission electron microscopy, Macromolecules 46 (21) (2013) 8589-8595. 
[93] E.C. Muniz, G. Geuskens, Compressive elastic modulus of polyacrylamide hydrogels and semi-IPNs with poly(N-isopropylacrylamide), Macromolecules 34 (13) (2001) 4480-4484.

[94] G.G. Ferruzzi, N. Pan, W.H. Casey, Mechanical properties of gellan and polyacrylamide gels with implications for soil stabilization, Soil Sci. 165 (10) (2000) $778-792$.

[95] A. Gutowska, Y.H. Bae, H. Jacobs, J. Feijen, S.W. Kim, Thermosensitive interpenetrating polymer networks - synthesis, characterization, and macromolecular release, Macromolecules 27 (15) (1994) 4167-4175.

[96] M.A. Haque, T. Kurokawa, J.P. Gong, Anisotropic hydrogel based on bilayers: color, strength, toughness, and fatigue resistance, Soft Matter 8 (31) (2012) 8008-8016.

[97] A.T. Paulino, A.G.B. Pereira, A.R. Fajardo, K. Erickson, M.J. Kipper, E.C. Muniz, et al, Natural polymer-based magnetic hydrogels: potential vectors for remote-controlled drug release, Carbohydr. Polym. 90 (3) (2012) 1216-1225.

[98] R.H. Pritchard, E.M. Terentjev, Swelling and de-swelling of gels under external elastic deformation, Polymer 54 (26) (2013) 6954-6960.

[99] A. Rashidzadeh, A. Olad, D. Salari, A. Reyhanitabar, On the preparation and swelling properties of hydrogel nanocomposite based on sodium alginateg-poly (acrylic acid-co-acrylamide)/clinoptilolite and its application as slow release fertilizer, J. Polym. Res. 21 (2) (2014) 1-15.

[100] L.H. Sperling, Introduction to Physical Polymer Science, J. Wiley, Pennsylvania, Bethlehem, 2006.

[101] P.J. Flory, Statistical mechanics of swelling of network structures, J. Chem. Phys. 18 (1) (1950) 108-111.

[102] W. Moench, J. Dehnert, E. Jaufmann, H. Zappe, Flory-Huggins swelling of polymer Bragg mirrors, Appl. Phys. Lett. 89 (16) (2006) $164104.1-164104.3$.

[103] A.G.G. Blanco, E. Casanova, M.E. Pirela, A. Briceño, Mathematical modeling of hydrogels swelling based on the finite element method, Appl. Math. 4 (2013) 161-170.

[104] P.J. Flory, Principles of Polymer Chemistry, Cornell University Press, Ithaca, New York, United States, 1953.

[105] A.T. Paulino, M.R. Guilherme, A.V. Reis, G.M. Campese, E.C. Muniz, J. Nozaki, Removal of methylene blue dye from an aqueous media using superabsorbent hydrogel supported on modified polysaccharide, J. Colloid Interface Sci. 301 (1) (2006) 55-62.

[106] A. Katchalsky, Rapid swelling and deswelling of reversible gels of polymeric acids by ionization, Experientia 5 (8) (1949) 319-320.

[107] L. Brannon-Peppas, N.A. Peppas, The equilibrium swelling behavior of porous and non-porous hydrogels, in: Absorbent Polymer Technology, Elsevier, Amsterdam, Netherlands, 1990, pp. 67-751.

[108] B. Ni, M. Liu, S. Lue, Multifunctional slow-release urea fertilizer from ethylcellulose and superabsorbent coated formulations, Chem. Eng. J. 155 (3) (2009) 892-898

[109] S. Noppakundilograt, N. Pheatcharat, S. Kiatkamjornwong, Multilayer-coated NPK compound fertilizer hydrogel with controlled nutrient release and water absorbency, J. Appl. Polym. Sci. 132 (2) (2015) 41249-41250.

[110] A.T. Paulino, L.A. Belfiore, L.T. Kubota, E.C. Muniz, V.C. Almeida, E.B. Tambourgi, Effect of magnetite on the adsorption behavior of Pb(II), Cd(II), and $\mathrm{Cu}(\mathrm{II})$ in chitosan-based hydrogels, Desalination 275 (1-3) (2011) 187-196.

[111] T. Katayama, M. Nakauma, S. Todoriki, G.O. Phillips, M. Tada, Radiation-induced polymerization of gum arabic (Acacia senegal) in aqueous solution, Food Hydrocolloids 20 (7) (2006) 983-989.

[112] M.R. de Moura, A.F. Rubira, E.C. Muniz, Semi-IPN hydrogels based on alginate-Ca ${ }^{2+}$ network and PNIPAAm: hydrophilic, morphological and mechanical properties, Polimeros-Ciencia E Tecnologia 18 (2) (2008) 132-137.

[113] B.R. Facin, B. Moret, D. Baretta, L.A. Belfiore, A.T. Paulino, Immobilization and controlled release of $\beta$-galactosidase from chitosan-grafted hydrogels, Food Chem. 179 (2015) 44-51.

[114] C.S. Brazel, N.A. Peppas, Mechanisms of solute and drug transport in relaxing, swellable, hydrophilic glassy polymers, Polymer 40 (12) (1999) 33833398.

[115] M. Mahkam, Modified chitosan cross-linked starch polymers for oral insulin delivery, J. Bioactive Compatible Polym. 25 (4) (2010) 406-418.

[116] F. Song, L.-M. Zhang, J.-F. Shi, N.-N. Li, Novel casein hydrogels: formation, structure and controlled drug release, Colloids Surf. B - Biointerfaces 79 (1) (2010) 142-148.

[117] W. Wang, Y. Kang, A. Wang, Synthesis, characterization and swelling properties of guar gum-g-poly(sodium acrylate-co-styrene)/muscovite superabsorbent composites, Sci. Technol. Adv. Mater. 11 (2) (2010) 1-10.

[118] K.Y. Lee, D.J. Mooney, Hydrogels for tissue engineering, Chem. Rev. 101 (7) (2001) 1869-1879.

[119] A. Shalviri, Q. Liu, M.J. Abdekhodaie, X.Y. Wu, Novel modified starch-xanthan gum hydrogels for controlled drug delivery: synthesis and characterization, Carbohydr. Polym. 79 (4) (2010) 898-907.

[120] J.I. Simionato, A.T. Paulino, J.C. Garcia, J. Nozaki, Adsorption of aluminium from wastewater by chitin and chitosan produced from silkworm chrysalides, Polym. Int. 55 (11) (2006) 1243-1248.

[121] A.T. Paulino, A.R. Fajardo, A.P. Junior, E.C. Muniz, E.B. Tambourgi, Two-step synthesis and properties of amagnetic-field-sensitive modified maltodextrin-based hydrogel, Polym. Int. 60 (9) (2011) 1324-1333.

[122] Q. Chen, L. Zhu, C. Zhao, Q. Wang, J. Zheng, A robust, one-pot synthesis of highly mechanical and recoverable double network hydrogels using thermoreversible sol-gel polysaccharide, Adv. Mater. 25 (30) (2013) 4171-4176.

[123] K. Ito, Novel cross-linking concept of polymer network: synthesis, structure, and properties of slide-ring gels with freely movable junctions, Polym. J. 39 (6) (2007) 489-499.

[124] D.G. Barrett, D.E. Fullenkamp, L. He, N. Holten-Andersen, K.Y.C. Lee, P.B. Messersmith, PH-based regulation of hydrogel mechanical properties through mussel-inspired chemistry and processing, Adv. Funct. Mater. 23 (9) (2013) 1111-1119.

[125] H.A. Barnes, Thixotropy - a review, J. Non-Newtonian Fluid Mech. 70 (1-2) (1997) 1-33.

[126] H.A.H.J. Barnes, K. Walters, An Introduction to Rheology, Elsevier, Amsterdam, Netherlands, 1996.

[127] D.S. Jones, Dynamic mechanical analysis of polymeric systems of pharmaceutical and biomedical significance, Int. J. Pharma. 179 (2) (1999) 167-178.

[128] D.Q.M. Craig, F.A. Johnson, Pharmaceutical applications of dynamic-mechanical thermal-analysis, Thermochim. Acta 248 (1995) $97-115$.

[129] M.N. Collins, C. Birkinshaw, Physical properties of crosslinked hyaluronic acid hydrogels, J. Mater. Sci. - Mater. Med. 19 (11) (2008) 3335-3343.

[130] K.R. Miller, M.D. Soucek, Photopolymerization of biocompatible films containing poly(lactic acid), Eur. Polym. J. 48 (12) (2012) $2107-2116$.

[131] Y. Zheng, P. Li, J. Zhang, A. Wang, Study on superabsorbent composite XVI. Synthesis, characterization and swelling behaviors of poly(sodium acrylate)/vermiculite superabsorbent composites, Eur. Polym. J. 43 (5) (2007) 1691-1698.

[132] P.J. Molloy, M.J. Smith, M.J. Cowling, The effects of salinity and temperature on the behaviour of polyacrylamide gels, Mater. Des. 21 (3) (2000) 169174.

[133] M.R. Guilherme, A.V. Reis, A.T. Paulino, T.A. Moia, L.H.C. Mattoso, E.B. Tambourgi, Pectin-based polymer hydrogel as a carrier for release of agricultural nutrients and removal of heavy metals from wastewater, J. Appl. Polym. Sci. 117 (6) (2010) 3146-3154.

[134] A.T. Paulino, M.R. Guilherme, L.H.C. Mattoso, E.B. Tambourgi, Smart hydrogels based on modified gum arabic as a potential device for magnetic biomaterial, Macromol. Chem. Phys. 211 (11) (2010) 1196-1205.

[135] B. Ni, M. Liu, S. Lu, L. Xie, Y. Wang, Environmentally friendly slow-release nitrogen fertilizer, J. Agric. Food Chem. 59 (18) (2011) $10169-10175$.

[136] A. Pourjavadi, M. Sadeghi, H. Hosseinzadeh, Modified carrageenan. 5. Preparation, swelling behavior, salt- and pH-sensitivity of partially hydrolyzed crosslinked carrageenan-graft-polymethacrylamide superabsorbent hydrogel, Polym. Adv. Technol. 15 (11) (2004) 645-653.

[137] C.W.d.Q. Brito, F.H.A. Rodrigues, M.V.d.S. Fernandes, L.R.D. da Silva, N.M.P.S. Ricardo, J.P.A. Feitosa, et al, Synthesis and characterization of poly(acrylamide-co-acrylate) and kaolin hydrogel composites: effect of the constitution of different kaolins from northeastern Brazil, Quimica Nova 36 (1) (2013) 40-45.

[138] A.I. Raafat, M. Eid, M.B. El-Arnaouty, Radiation synthesis of superabsorbent CMC based hydrogels for agriculture applications, Nucl. Instrum. Meth. Phys. Res. Sect. B - Beam Interact. Mater. Atoms 283 (2012) 71-76. 
[139] G.R. Mahdavinia, M.J. Zohuriaan-Mehr, A. Pourjavadi, Modified chitosan III, superabsorbency, salt- and pH-sensitivity of smart ampholytic hydrogels from chitosan-g-PAN, Polym. Adv. Technol. 15 (4) (2004) 173-180.

[140] D. Castel, A. Ricard, R. Audebert, Swelling of anionic and cationic starch-based superabsorbents in water and saline solution, J. Appl. Polym. Sci. 39 (1) (1990) 11-29.

[141] M.E. Trenkel, International Fertilizer Industry Association, Stratospheric Ozone, HMSO, London, England, 1997.

[142] D.W.V.M. Davidson, F.X. Gu, Controlled root targeted delivery of fertilizer using an ionically crosslinked carboxymethyl cellulose hydrogel matrix, Springerplus 2 (2013) 1-9.

[143] X. Li, W. Wu, W. Liu, Synthesis and properties of thermo-responsive guar gum/poly(N-isopropylacrylamide) interpenetrating polymer network hydrogels, Carbohydr. Polym. 71 (3) (2008) 394-402.

[144] F.A. Aouada, M.R. de Moura, E.d.A. Menezes, A.R. de Araujo Nogueira, L.H. Capparelli Mattoso, Hydrogel synthesis and kinetics of ammonium and potassium release, Revista Brasileira De Ciencia Do Solo 32 (4) (2008) 1643-1649.

[145] W. Zhou, Y. Lou, L. Ren, Y. Han, Y. Meng, L. Wu, Application of controlled-release nitrogen fertilizer decreased methane emission in transgenic rice from a paddy soil, Water Air Soil Pollut. 225 (3) (2014) 2-7.

[146] Saruchi, B.S. Kaith, R. Jindal, G.S. Kapur, Enzyme-based green approach for the synthesis of gum tragacanth and acrylic acid cross-linked hydrogel: its utilization in controlled fertilizer release and enhancement of water-holding capacity of soil, Iran. Polym. J. 22 (8) (2013) 561-570.

[147] L. Wu, M. Liu, Preparation and properties of chitosan-coated NPK compound fertilizer with controlled-release and water-retention, Carbohydr. Polym. 72 (2) (2008) 240-247.

[148] X. Wang, S. Lu, C. Gao, X. Xu, Y. Wei, X. Bai, et al, Biomass-based multifunctional fertilizer system featuring controlled-release nutrient, water retention and amelioration of soil, RSC Adv. 4 (35) (2014) 18382-18390.

[149] A. Shaviv, Advances in controlled-release fertilizers, Adv. Agronomy 71 (71) (2001) 1-49.

[150] P.H.R.H. Brunner, Practical Handbook of Material Flow Analysis - Advanced Methods in Resource and Waste Management Series, Lewis Publishers, Boca Raton, Florida, United States, 2004.

[151] M. Chen, J. Chen, F. Sun, Estimating nutrient releases from agriculture in China: an extended substance flow analysis framework and a modeling tool, Sci. Total Environ. 408 (21) (2010) 5123-5136.

[152] A. Shaviv, R.L. Mikkelsen, Controlled-release fertilizers to increase efficiency of nutrient use and minimize environmental degradation - a review, Nutrient Cycling Agroecosyst. 35 (1993) 1-12.

[153] S.K. Basu, N. Kumar, Mathematical model and computer simulation for release of nutrients from coated fertilizer granules, Math. Comput. Simulation 79 (3) (2008) 634-646.

[154] A. Bortolin, F.A. Aouada, L.H.C. Mattoso, C. Ribeiro, Nanocomposite PAAm/methyl cellulose/montmorillonite hydrogel: evidence of synergistic effects for the slow release of fertilizers, J. Agric. Food Chem. 61 (31) (2013) 7431-7439.

[155] U. Shavit, M. Reiss, A. Shaviv, Wetting mechanisms of gel-based controlled-release fertilizers, J. Control. Release 88 (1) (2003) 71-83.

[156] C. Du, J. Zhou, A. Shaviv, H. Wang, Mathematical model for potassium release from polymer-coated fertiliser, Biosyst. Eng. 88 (3) (2004) 395-400.

[157] S.K. Basu, N. Kumar, J.P. Srivastava, Modeling NPK release from spherically coated fertilizer granules, Simulation Model. Practice Theory 18 (6) (2010) $820-835$.

[158] S. Wang, A.K. Alva, Y. Li, M. Zhang, A rapid technique for prediction of nutrient release from polymer coated controlled release fertilizers, Open J. Soil Sci. 1 (2011) 40-44.

[159] U. Shavit, A. Shaviv, G. Shalit, D. Zaslavsky, Release characteristics of a new controlled release fertilizer, J. Control. Release 43 (2-3) (1997) 131-138.

[160] L. Masaro, X.X. Zhu, Physical models of diffusion for polymer solutions, gels and solids, Progr. Polym. Sci. 24 (5) (1999) $731-775$.

[161] T. Zheng, Y. Liang, S. Ye, Z. He, Superabsorbent hydrogels as carriers for the controlled-release of urea: experiments and a mathematical model describing the release rate, Biosyst. Eng. 102 (1) (2009) 44-50.

[162] A. Tsoularis, J. Wallace, Analysis of logistic growth models, Math. Biosci. 179 (1) (2002) 21-55.

[163] A.V.G.M. Reis, A.F. Rubira, E.C. Muniz, Mathematical model for the prediction of the overall profile of in vitro solute release from polymer networks, J. Colloid Interface Sci. 310 (1) (2007) 7.

[164] A.J.M. Valente, S.M.A. Cruz, M.C. Morán, D.B. Murtinho, E.C. Muniz, M.G. Miguel, Release of DNA from cryogel PVA-DNA membranes. eXPRESS, Polym. Lett. 4 (8) (2010) 480-487.

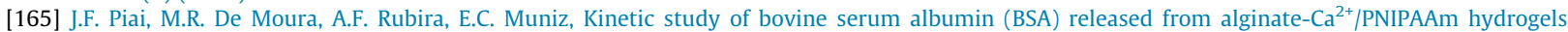
Macromol. Symposia 266 (1) (2008) 108-113.

[166] R. Bossoni, A. Riul, A.J.M. Valente, A.F. Rubira, E.C. Muniz, Release of Vitamin B12 and Diclofenac Potassium from N,N-dimethylacrylamide-modified Arabic gum hydrogels - the partition-diffusion model, J. Brazil. Chem. Soc. 25 (6) (2014) 1124-1134.

[167] M.T. Vangenuchten, A closed-form equation for predicting the hydraulic conductivity of unsaturated soils, Soil Sci. Soc. Am. J. 44 (5) (1980) 892-898.

[168] C.K.S. Pillai, Challenges for natural monomers and polymers: novel design strategies and engineering to develop advanced polymers, Designed Monomers Polym. 13 (2) (2010) 87-121.

[169] M.J. Zohuriaan-Mehr, H. Omidian, S. Doroudiani, K. Kabiri, Advances in non-hygienic applications of superabsorbent hydrogel materials, J. Mater. Sci. 45 (21) (2010) 5711-5735.

[170] M. Kataja, A. Rybin, J. Timonen, Permeability of highly compressible porous-medium, J. Appl. Phys. 72 (4) (1992) 1271-1274.

[171] R. Bhattacharyya, S.K. Ray, B. Mandal, A systematic method of synthesizing composite superabsorbent hydrogels from crosslink copolymer for removal of textile dyes from water, J. Indust. Eng. Chem. 19 (4) (2013) 1191-1203.

[172] Y. Zhou, S. Fu, L. Zhang, H. Zhan, Superabsorbent nanocomposite hydrogels made of carboxylated cellulose nanofibrils and CMC-g-p(AA-co-AM), Carbohydr. Polym. 97 (2) (2013) 429-435.

[173] K. Hemvichian, A. Chanthawong, P. Suwanmala, Synthesis and characterization of superabsorbent polymer prepared by radiation-induced graft copolymerization of acrylamide onto carboxymethyl cellulose for controlled release of agrochemicals, Radiat. Phys. Chem. 103 (2014) 167-171.

[174] W. Wang, A. Wang, Nanocomposite of carboxymethyl cellulose and attapulgite as a novel pH-sensitive superabsorbent: synthesis, characterization and properties, Carbohydr. Polym. 82 (1) (2010) 83-91.

[175] Y. Wang, X. Shi, W. Wang, A. Wang, Synthesis, characterization, and swelling behaviors of a pH-responsive CMC-g-poly(AA-co-AMPS) superabsorbent hydrogel, Turkish J. Chem. 37 (1) (2013) 149-159.

[176] J. Kuang, K.Y. Yuk, K.M. Huh, Polysaccharide-based superporous hydrogels with fast swelling and superabsorbent properties, Carbohydr. Polym. 83 (1) (2011) 284-290.

[177] K. Zhong, X.-L. Zheng, X.-Y. Mao, Z.-T. Lin, G.-B. Jiang, Sugarcane bagasse derivative-based superabsorbent containing phosphate rock with waterfertilizer integration, Carbohydr. Polym. 90 (2) (2012) 820-826.

[178] T. Jamnongkan, S. Kaewpirom, Potassium release kinetics and water retention of controlled-release fertilizers based on chitosan hydrogels, J. Polym. Environ. 18 (3) (2010) 413-421.

[179] A. Martinez-Ruvalcaba, J.C. Sanchez-Diaz, F. Becerra, L.E. Cruz-Barba, A. Gonzalez-Alvarez, Swelling characterization and drug delivery kinetics of polyacrylamide-co-itaconic acid/chitosan hydrogels, Express Polym. Lett. 3 (1) (2009) 25-32.

[180] E.C. Gil, A.I. Colarte, B. Bataille, I. Caraballo, Estimation of the percolation thresholds in lobenzarit disodium native dextran matrix tablets, AAPS PharmSciTech 8 (2007) 1-7.

[181] H. Agaba, L.J.B. Orikiriza, J. Obua, J.D. Kabasa, M. Worbes, A. Hüttermann, Hydrogel amendment to sandy soil reduces irrigation frequency and improves the biomass of Agrostis stolonifera, Agric. Sci. 2 (4) (2011) 544-550.

[182] C. Demitri, F. Scalera, M. Madaghiele, A. Sannino, A. Maffezzoli, Potential of cellulose-based superabsorbent hydrogels as water reservoir in agriculture, Int. J. Polym. Sci. 2013 (2013) 1-6. 
[183] P.C. Parvathy, A.N. Jyothi, Rheological and thermal properties of saponified cassava starch-g-poly(acrylamide) superabsorbent polymers varying in grafting parameters and absorbency, J. Appl. Polym. Sci. 131 (11) (2014) 40368-40379.

[184] P. Chen, W. Zhang, W. Luo, Y. Fang, Synthesis of superabsorbent polymers by irradiation and their applications in agriculture, J. Appl. Polym. Sci. 93 (4) (2004) 1748-1755.

[185] H.A.A. El-Rehim, Characterization and possible agricultural application of polyacrylamide/sodium alginate crosslinked hydrogels prepared by ionizing radiation, J. Appl. Polym. Sci. 102 (6) (2006) 3572-3580.

[186] A. Singh, D.J. Sarkar, A.K. Singh, R. Parsad, A. Kumar, B.S. Parmar, Studies on novel nanosuperabsorbent composites: swelling behavior in different environments and effect on water absorption and retention properties of sandy loam soil and soil-less medium, J. Appl. Polym. Sci. 120 (3) (2011) $1448-1458$.

[187] Y. Han, X. Yu, P. Yang, B. Li, L. Xu, C. Wang, Dynamic study on water diffusivity of soil with super-absorbent polymer application, Environ. Earth Sci. 69 (1) (2013) 289-296.

[188] E.A. Ferreira, V.A. Silva, E.A. Silva, H.d.R.O. Silveira, Eficiência do hidrogel e respostas fisiológicas de mudas de cultivares apirênicas de citros sob défice hídrico cultivars seedlings under water deficit, Pesquisa Agropecuária Tropical 44 (2) (2014) 158-165.

[189] J.M.K. Akhter, K.A. Malik, A. Mardan, M. Ahmad, M.M. Iqbal, Effects of hydrogel amendment on water storage of sandy loam and loam soils and seedling growth of barley, wheat and chickpea, Plant Soil Environ. 50 (10) (2004) 463-469.

[190] O.A. El-Hady, S.A. Abo-Sedera, Conditioning effect of composts and acrylamide hydrogels on a sandy calcareous soil. II-Physico-bio-chemical properties of the soil, Int. J. Agric. Biol. 8 (2006) 876-884.

[191] S. Kiatkamjornwong, Superabsorbent polymers and superabsorbent polymer composites, ScienceAsia 33 (2007) 39-43.

[192] M.J. Zohuriaan-Mehr, K. Kabiri, Superabsorbent polymer materials: a review, Iran. Polym. J. 17 (6) (2008) 451-477.

[193] P. Leciejewski, The effect of hydrogel additives on the water retention curve of sandy soil from forest nursery in Julinek, J. Water Land Develop. 13a (2009) 239-247.

[194] L.O. Ekebafe, D.E. Ogbeifun, F.E. Okieimen, Polymer applications in agriculture, Biokemistri 23 (2) (2011) 81-89.

[195] F. Nnadi, C. Brave, Environmentally friendly superabsorbent polymers for water conservation in agricultural lands, J. Soil Sci. Environ. Manage. 2 (7) (2011) 206-211.

[196] S. Shooshtarian, J. Abedi-Kupai, A. TehraniFar, Evaluation of application of superabsorbent polymers in green space of arid and semi-arid regions with emphasis on Iran, J. Biodiversity Ecol. Sci. 1 (4) (2011) 258-269.

[197] H. Emami, A.R. Astaraei, Effect of organic and inorganic amendments on parameters of water retention curve, bulk density and aggregate diameter of a saline-sodic soil, J. Agric. Sci. Technol. 14 (2012) 1625-1636.

[198] T.D. Landis, D.L. Haase, Applications of hydrogels in the nursery and during outplanting, in: USDA Forest Service Proceedings, RMRS-P-68, 2012, pp. 53-58.

[199] M.O. Ekebafe, L.O. Ekebafe, M. Maliki, Utilisation of biochar and superabsorbent polymers for soil amendment, Sci. Progr. 96 (1) (2013) 85-94.

[200] S.S. Lee, S.X. Chang, Y.-Y. Chang, Y.S. Ok, Commercial versus synthesized polymers for soil erosion control and growth of Chinese cabbage, Springerplus 2 (2013) 534-544.

[201] A.S.G. Magalhães, M.P.A. Neto, M.N. Bezerra, J.P.A. Feitosa, Superabsorbent hydrogel composite with minerals aimed at water sustainability, J. Brazil. Chem. Soc. 24 (2) (2013) 304-313.

[202] I. Alemzadeh, M. Vossoughi, Controlled release of paraquat from poly vinyl alcohol hydrogel, Chem. Eng. Process. 41 (8) (2002) $707-710$.

[203] E.R. Kenawy, Biologically active polymers: controlled-release formulations based on crosslinked acrylamide gel derivatives, React. Funct. Polym. 36 (1) (1998) 31-39.

[204] A.R. Kulkarni, K.S. Soppimath, T.M. Aminabhavi, A.M. Dave, M.H. Mehta, Glutaraldehyde crosslinked sodium alginate beads containing liquid pesticide for soil application, J. Control. Release 63 (1-2) (2000) 97-105.

[205] M.Y. Guo, M.Z. Liu, F.L. Zhan, L. Wu, Preparation and properties of a slow-release membrane-encapsulated urea fertilizer with superabsorbent and moisture preservation, Indust. Eng. Chem. Res. 44 (12) (2005) 4206-4211.

[206] R. Liang, H. Yuan, G. Xi, Q. Zhou, Synthesis of wheat straw-g-poly(acrylic acid) superabsorbent composites and release of urea from it, Carbohydr. Polym. 77 (2) (2009) 181-187.

[207] A. Rashidzadeh, A. Olad, Slow-released NPK fertilizer encapsulated by NaAlg-g-poly(AA-co-AAm)/MMT superabsorbent nanocomposite, Carbohydr. Polym. 114 (2014) 269-278.

[208] E.V.R. Campos, Oliveira.J.Z. De, L.F. Fraceto, B. Singh, Polysaccharides as safer release systems for agrochemicals, Agronomy Sustain. Develop. (2014) $1-20$.

[209] F.L. Zhan, M.Z. Liu, M.Y. Guo, L. Wu, Preparation of superabsorbent polymer with slow-release phosphate fertilizer, J. Appl. Polym. Sci. 92 (5) (2004) $3417-3421$.

[210] L. Wu, M. Liu, R. Liang, Preparation and properties of a double-coated slow-release NPK compound fertilizer with superabsorbent and waterretention, Bioresour. Technol. 99 (3) (2008) 547-554.

[211] L. Xie, M. Liu, B. Ni, X. Zhang, Y. Wang, Slow-release nitrogen and boron fertilizer from a functional superabsorbent formulation based on wheat straw and attapulgite, Chem. Eng. J. 167 (1) (2011) 342-348.

[212] S. Jin, Y. Wang, J. He, Y. Yang, X. Yu, G. Yue, Preparation and properties of a degradable interpenetrating polymer networks based on starch with water retention, amelioration of soil, and slow release of nitrogen and phosphorus fertilizer, J. Appl. Polym. Sci. 128 (1) (2013) 407-415.

[213] K. Zhong, Z.-T. Lin, X.-L. Zheng, G.-B. Jiang, Y.-S. Fang, X.-Y. Mao, et al, Starch derivative-based superabsorbent with integration of water-retaining and controlled-release fertilizers, Carbohydr. Polym. 92 (2) (2013) 1367-1376.

[214] B. Azeem, K. KuShaari, Z.B. Man, A. Basit, T.H. Thanh, Review on materials \& methods to produce controlled release coated urea fertilizer, J. Control. Release 181 (2014) 11-21.

[215] A.T. Paulino, M.R. Guilherme, A.V. Reis, G.M. Campese, E.B. Tambourgi, J. Nozaki, E.C. Muniz, Capacity of adsorption of $\mathrm{Pb}^{2+}$ and $\mathrm{Ni}^{2+}$ from aqueous solutions by chitosan produced from silkworm chrysalides in different degrees of deacetylation, J. Hazard. Mater. 147 (1-2) (2007) 139-147.

[216] S. Sharma, A. Dua, A. Malik, Polyaspartic acid based superabsorbent polymers, Eur. Polym. J. 59 (2014) 363-376.

[217] K. Kabiri, H. Omidian, M.J. Zohuriaan-Mehr, S. Doroudiani, Superabsorbent hydrogel composites and nanocomposites: a review, Polym. Compos. 32 (2) (2011) 277-289.

[218] C. Chang, L. Zhang, Cellulose-based hydrogels: present status and application prospects, Carbohydr. Polym. 84 (1) (2011) 40-53.

[219] V.K. Thakur, M.K. Thakur, Recent trends in hydrogels based on psyllium polysaccharide: a review, J. Cleaner Prod. 82 (1) (2014) 1-15.

[220] J. Wu, Y. Wei, J. Lin, S. Lin, Study on starch-graft-acrylamide/mineral powder superabsorbent composite, Polymer 44 (21) (2003) 6513-6520.

[221] W.-F. Lee, L.-G. Yang, Superabsorbent polymeric materials. XII. Effect of montmorillonite on water absorbency for poly(sodium acrylate) and montmorillonite nanocomposite superabsorbents, Appl. Polym. 92 (5) (2004) 3422-3429.

[222] J. Zhang, R. Liu, A. Li, A. Wang, Preparation, swelling behaviors and application of polyacrylamide/attapulgite superabsorbent composites, Polym. Adv. Technol. 17 (1) (2006) 12-19.

[223] H.J. Prado, M. Matulewicz, Cationization of polysaccharides: a path to greener derivatives with many industrial applications, Eur. Polym. J. 52 (2014) 53-75.

[224] M.J. Zohuriaan-Mehr, H. Omidian, S. Doroudiani, K. Kabiri, Advances in non-hygienic applications of superabsorbent hydrogel materials, J. Mater. Sci. 45 (2010) 5711-5735. 